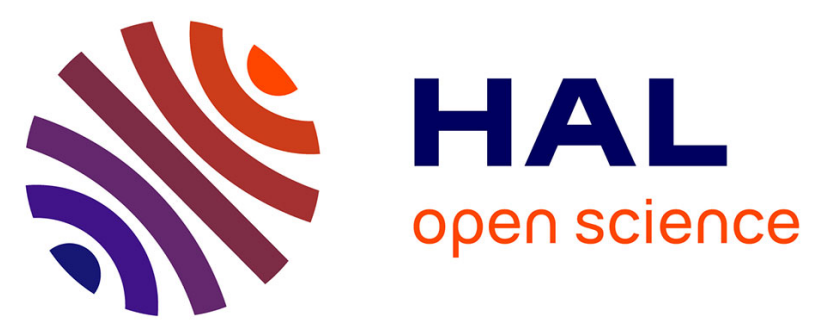

\title{
Magnetic fingerprinting of fluvial suspended particles in the context of soil erosion: example of the Canche River watershed (Northern France)
}

Christine Franke, Edouard Patault, Claire Alary, Nor-Edine Abriak, France Lagroix

\section{To cite this version:}

Christine Franke, Edouard Patault, Claire Alary, Nor-Edine Abriak, France Lagroix. Magnetic fingerprinting of fluvial suspended particles in the context of soil erosion: example of the Canche River watershed (Northern France). Geochemistry, Geophysics, Geosystems, 2020, 21 (5), pp.e2019GC008836. 10.1029/2019GC008836 . hal-02538638

\section{HAL Id: hal-02538638 \\ https://hal.science/hal-02538638}

Submitted on 27 May 2020

HAL is a multi-disciplinary open access archive for the deposit and dissemination of scientific research documents, whether they are published or not. The documents may come from teaching and research institutions in France or abroad, or from public or private research centers.
L'archive ouverte pluridisciplinaire HAL, est destinée au dépôt et à la diffusion de documents scientifiques de niveau recherche, publiés ou non, émanant des établissements d'enseignement et de recherche français ou étrangers, des laboratoires publics ou privés. 


\section{Geochemistry, Geophysics, Geosystems}

\author{
RESEARCH ARTICLE \\ 10.1029/2019GC008836 \\ Key Point: \\ - This study employs a simple and \\ cost-effective technique from \\ environmental magnetism to trace \\ topsoil erosion input into rivers
}

Supporting Information:

- Supporting Information S1

Correspondence to:

C. Franke,

christine.franke@mines-paristech.fr

\section{Citation:}

Franke, C., Patault, E., Alary, C., Abriak, N.-E., \& Lagroix, F. (2020). Magnetic fingerprinting of fluvial suspended particles in the context of soil erosion: Example of the Canche River watershed (northern France). Geochemistry, Geophysics, Geosystems, 21, e2019GC008836. https://doi.org/ 10.1029/2019GC008836

Received 27 NOV 2019 Accepted 31 MAR 2020 Accepted article online 8 APR 2020

(c)2020. American Geophysical Union. All Rights Reserved.

\section{Magnetic Fingerprinting of Fluvial Suspended Particles in the Context of Soil Erosion: Example of the Canche River Watershed (Northern France)}

\author{
Christine Franke ${ }^{1}$ (D), Edouard Patault ${ }^{1,2,3}$ (D) Claire Alary ${ }^{2}$, Nor-Edine Abriak ${ }^{2}$, \\ and France Lagroix ${ }^{4}$ iD
}

${ }^{1}$ MINES ParisTech, PSL Research University, Center of Geosciences, Paris, France, ${ }^{2}$ IMT Lille Douai, University of Lille, Lille, France, ${ }^{3}$ Normandie University, UNIROUEN, UNICAEN, CNRS, M2C, FED-SCALE, Rouen, France, ${ }^{4}$ Université de Paris, Institut de physique du globe de Paris, CNRS, Paris, France

\section{Introduction}

Numerous studies on the complex aspects of sediment flux in fluvial systems have been undertaken (e.g., review of Haddadchi et al., 2013) in response to demands for efficient land use management and sediment control strategies. Different geochemical and sedimentological tracers have been investigated (geochemistry (Carter et al., 2003; Theuring et al., 2015; Vale et al., 2016), radionuclides (e.g., Evrard et al., 2010; Le Gall et al., 2016), and sediment color (Martínez-Carreras et al., 2010; Poulenard et al., 2009) and used to estimate and model transported sediment yields as well as to identify diffuse or point sources over time and space. Despite these efforts, the need for rapid and easy to interpret proxy parameters persists (Guzmán et al., 2013). Environmental magnetic fingerprinting techniques applied to fluvial catchment studies have diversified over the last decades (e.g., Caitcheon, 1993; Dearing, 1987; Hatfield \& Maher, 2008; Maher et al., 2009; Motha et al., 2004; Oldfield et al., 1979; Russell et al., 2001; Slattery et al., 1995; Walling et al., 1979). Environmental magnetism provides the advantage of tracing the iron-bearing mineral fraction of the sediment. The ubiquity of iron in the environment leads to iron-bearing minerals being a traceable reactive phase in fluvial processes (e.g., runoff, sediment flux, accumulation, diagenesis of iron (hydr)oxides; Evans \& Heller, 2003; Maher, 2007). The most important challenge for magnetism-based proxies is determining the correct interpretation of the magnetic proxy parameters with respect to sampling protocol, sediment type, magnetic mineral phase assemblage, and range of particle size.

This study aims to develop a straightforward magnetic proxy parameter to trace the erosion of topsoils at the scale of a catchment in order to quantitatively model spatiotemporal sediment flux. The presented results are akin to the studies of Patault (2018), Patault, Alary, Franke, \& Abriak (2019), and Patault, Alary, Franke, Gauthier, \& Abriak (2019) in which other, more routinely used sediment tracer parameters (such as grain 


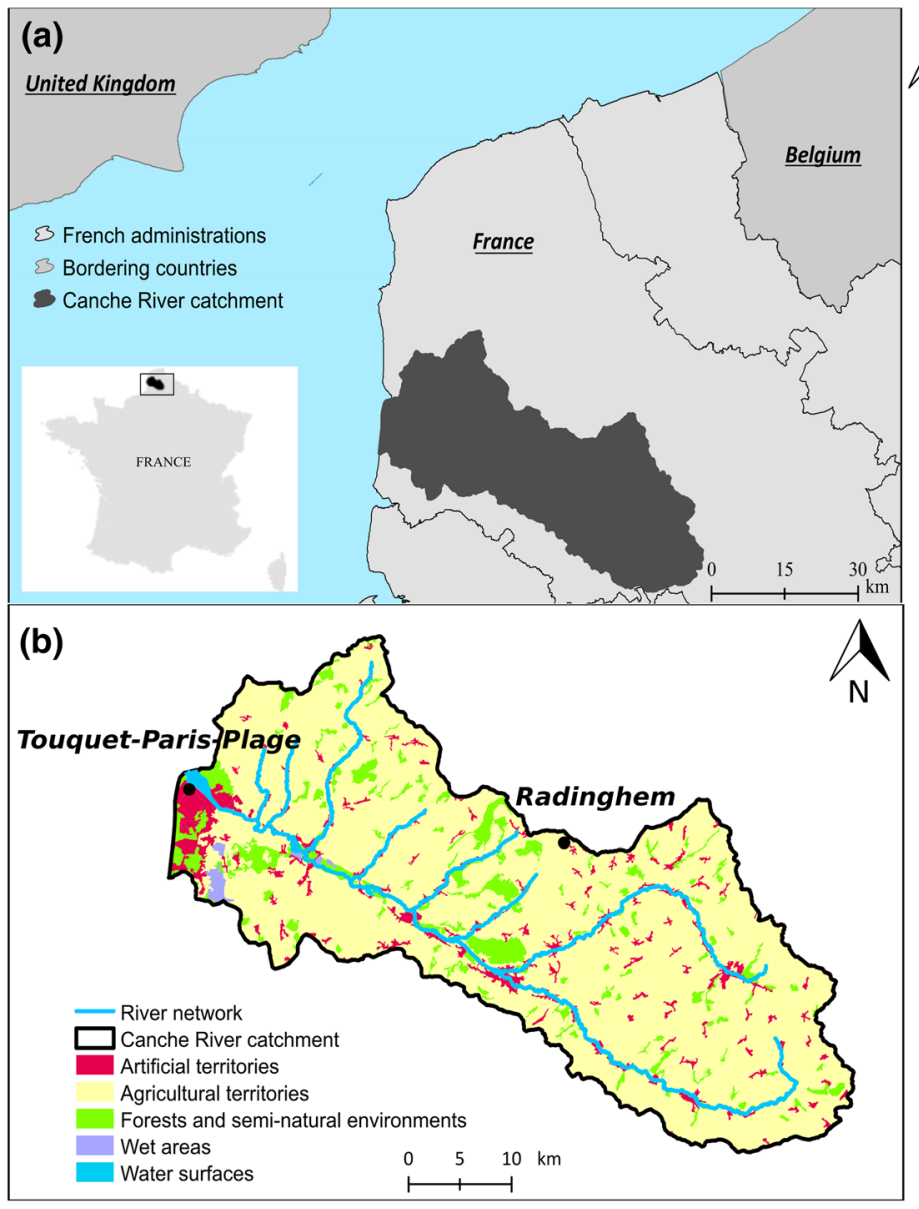

(c)

$\mathrm{N}$

$\mathrm{N}$
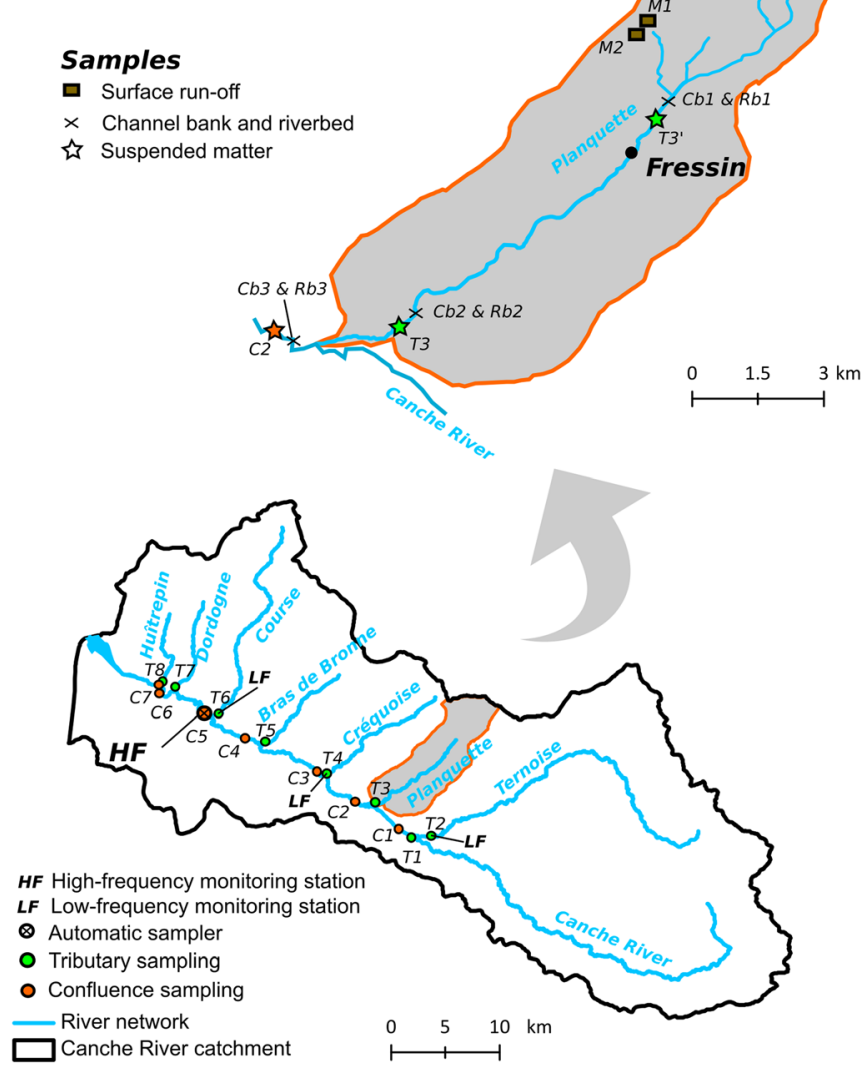

Figure 1. (a) Overview of the study area, (b) land cover of the Canche River watershed (source: Corine Land Cover 2012), and (c) location of sediment sampling sites in the Canche River watershed and in the Planquette River catchment.

size and geochemical elements) were used. We take advantage of the fact that soil particles have been found to carry a distinct magnetic mineral signature (e.g., Maher, 1998, 2007) compared to the average bedload of rivers. This is particularly true for catchments with relatively homogeneous lithology across its drainage area, as is the case for the Canche River catchment in Northern France.

\section{Materials and Methods}

\subsection{Study Area and Sampling Strategy}

\subsubsection{Context of the Canche River}

The Canche River watershed $\left(1,274 \mathrm{~km}^{2}\right.$; latitude: $50^{\circ} 25^{\prime} 53^{\prime \prime} \mathrm{N}$, longitude: $2^{\circ} 02^{\prime} 24^{\prime \prime} \mathrm{E}$; Figure 1a) is located in the European loess belt in Northern France. This region is characterized by oceanic climate conditions with a mean annual temperature of $10.3 \pm 0.7^{\circ} \mathrm{C}$ and a mean annual rainfall of $779 \pm 141 \mathrm{~mm}$ over the 1923-2017 time period (Abbeville station, NOAA-NCEI database; Lawrimore et al., 2016). Daily cumulative rainfall is recorded at two strategic locations in the catchment: Touquet-Paris-Plage and Radinghem (Figure 1b). Altitudes range from sea level at the catchment outlet to $207 \mathrm{~m}$ in upstream areas and slopes in the landscape commonly range around 2-3\%. The basin drains Pleistocene silts sitting on top of Seno-Turonian chalks. Land use is dominated by arable farming (>80\%; Figure $1 \mathrm{~b})$.

The watershed is characterized by a meandering drainage network dominated by the Canche River $(88 \mathrm{~km}$ length) and seven main tributaries: the Ternoise, the Planquette, the Créquoise, the Bras de Bronne, the Course, the Dordogne, and the Huîtrepin (Figure 1c). The discharge at each sampling site was quantified using three low-frequency monitoring stations ( $\Delta t=1$ day) on the Ternoise, the Course, and the Canche 
(positions indicated in Figure 1c as LF). Discharge for the ungauged catchment ( $Q_{\text {ungauged }}$ ) was calculated assuming similar rainfall and hydrological regimes in the entire Canche catchment. Values were extrapolated from the closest monitoring station by multiplying the discharge of the gauged catchment $\left(Q_{\text {gauged }}\right)$ with the appropriate fraction related to the ratio between the closest catchment area $\left(A_{\text {ungauged }}\right)$ and the catchment area at the monitoring station $\left(A_{\text {gauged }}\right)$ :

$$
Q_{\text {ungauged }}=Q_{\text {gauged }} \times \frac{A_{\text {ungauged }}}{A_{\text {gauged }}}
$$

where $Q$ represents the discharge in $\mathrm{m}^{3} \mathrm{~s}^{-1}$ and $A$ the area of the catchment in $\mathrm{km}^{2}$. For more details on the calculation of the flow discharge, please see also Patault, Alary, Franke, and Abriak (2019).

According to Andréassian et al. (2012), this method provides meaningful discharge estimates for ungauged catchments. Cross validation with the high-frequency monitoring station ( $\Delta t=15 \mathrm{~min}$; position indicated in Figure 1c as HF) on the Canche River at Attin suggests that the temporal variability in discharge is preserved, and the associated error was quantified to be $17 \%$. Mean annual discharge for the Canche River is estimated at $21 \mathrm{~m}^{3} \mathrm{~s}^{-1}$ with contributions from main subcatchments: Ternoise $\left(7 \mathrm{~m}^{3} \mathrm{~s}^{-1}\right)$, Planquette $\left(1.5 \mathrm{~m}^{3} \mathrm{~s}^{-1}\right)$, Créquoise $\left(2 \mathrm{~m}^{3} \mathrm{~s}^{-1}\right)$, Bras de Bronne $\left(2 \mathrm{~m}^{3} \mathrm{~s}^{-1}\right)$, Course $\left(4 \mathrm{~m}^{3} \mathrm{~s}^{-1}\right)$, Dordogne $\left(2.5 \mathrm{~m}^{3} \mathrm{~s}^{-1}\right)$, and Huîtrepin $\left(2 \mathrm{~m}^{3} \mathrm{~s}^{-1}\right)$. Considering the area of the Canche watershed $\left(1,274 \mathrm{~km}^{2}\right)$ and the annual sediment export estimation provided by the Artois-Picardie Water Agency (29-185 kt), the specific sediment yield (SSY) was estimated to range from $22.7-145 \mathrm{t} \mathrm{km}^{-2} \mathrm{yr}^{-1}$. The high amount of sediment flux in this territory is a direct consequence of soil erosion and surface runoff, which cause infrastructure damages and an important economic cost for local communities.

2.1.2. Sediment Sampling

Suspended particulate matter (SPM) was collected using sediment traps installed at each tributary outlet and confluence, as well as upstream of the Planquette River (Figure 1c). Sampling campaigns were conducted in winter 2015, winter 2016, spring 2016, summer 2016, autumn 2016, and one specific flood event on 3 February 2017. Cumulatively, 75 "seasonal SPM samples" were collected during these five sampling campaigns and are summarized in detail in Table 1. In addition, 24 SPM samples were collected at the Attin site during the 8 June 2016 flood event using a fixed automatic sampler (Aquamax 2; Table 2).

SPM samples were recovered using an experimental device adapted from previous studies described by Tessier (2003) and Kayvantash et al. (2017). The sediment traps (Figure 2) consist of 2 L polyethylene bottles, perforated at $5 \mathrm{~cm}$ from the top with two opposite bores (diameter $5 \mathrm{~cm}$ ). The bottle is attached to the riverbank with a rope and deposited in the channel. The device is held in place using either an additional rope or the combination of a wooden beam and rope. The whole device is weighted vertically in the water column (at $\sim 1 \mathrm{~m}$ depth below the surface) using ballast that is adapted to the river flow speed. Traps usually capture between 50 and $100 \mathrm{~g}$ of sediment during a 5 to 7 day collection period. Kayvantash et al. (2017) observed a homogeneous grain size selection when sampling near the water surface at different locations and a variable grain size selection when the sampling bottle is positioned at difference vertical positions in the river channel.

The comparison of SPM samples recovered by sediment traps and by an automatic sampler in this study allowed estimation of the sampling efficiency of the finest grain size fraction. Results are presented and discussed in section 3.2.

During the winter 2017 flood event, the following sampling strategies were deployed and realized. Two distinct surface runoff samples were sampled using sediment traps installed at the outlet of the Pommeroye River (Figure 1c). These surface runoff samples, M1 and M2 (Table 2), are topsoil (A-horizon) material laden runoff (see image in Figure 3a) collected by traps hooked to an existing Venturi channel designed to monitor hydro-sedimentary transfer in the small Pommeroye agricultural catchment (Figure 2; see also Patault et al., 2019b). Sampling sites T3 and T3' downstream of the confluence with the Planquette River (see Figure 1c for locations) were equipped with parallel sediment traps from which SPM were collected from four traps (a, b, c, and d) at each site. Finally, an SPM sample was collected at site C2 downstream of the confluence of the Planquette River with the Canche River (see Figure 1c). Sediment traps were deployed 1 day before the start of the erosive event ( 3 February 2017) and were recovered at the end of the event (6 February 2017). Each trap recovered $200-500 \mathrm{mg}$ of sediment. A total of six channel bank (Cb) sediment samples representing 


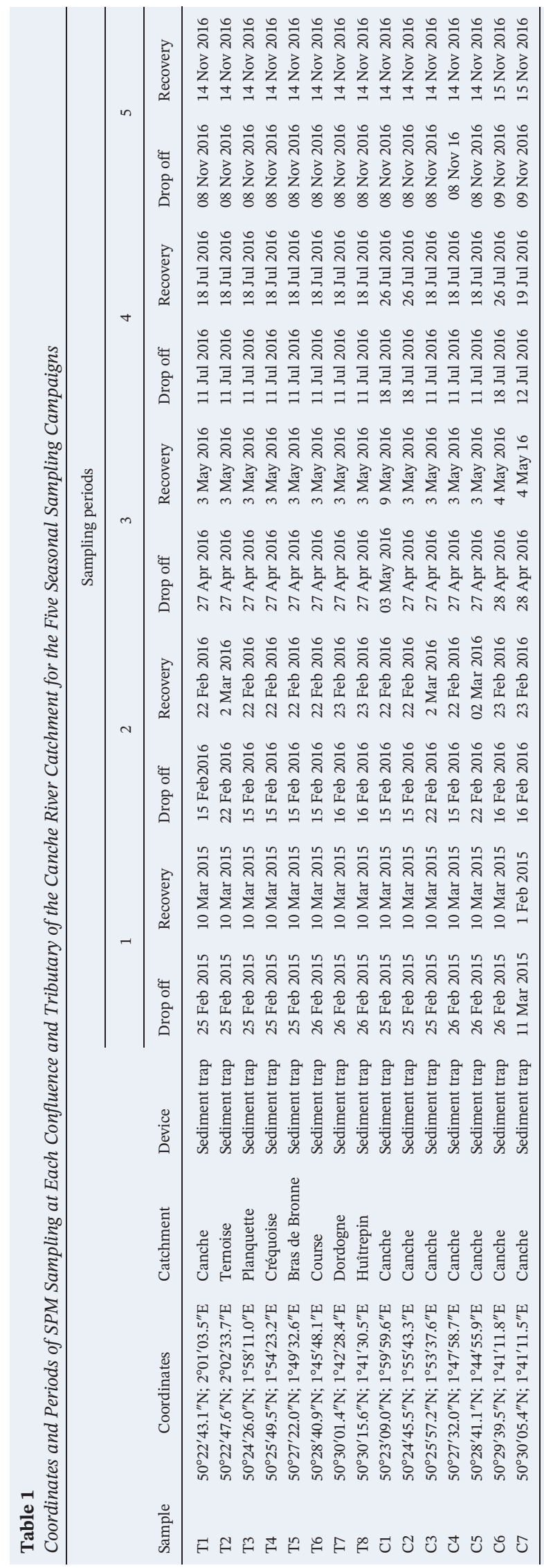


Table 2

Coordinates and Periods of Surface Runoff (M), Channel Bank (Cb), River Bed (Rb), and Suspended Particulate Matter (SPM) Sampled in the Canche River Catchment During the Winter 2017 and Spring 2016 Flood Events

\begin{tabular}{|c|c|c|c|c|c|c|c|}
\hline Sample & Coordinates & Catchment & Nature & Device & Date of sampling & Drop off & Recovery \\
\hline M1 & $50^{\circ} 28^{\prime} 12.6^{\prime \prime} \mathrm{N} ; 2^{\circ} 03^{\prime} 44.5^{\prime \prime} \mathrm{E}$ & Planquette & Surface runoff & Sediment trap & 3 Feb 2017 & & \\
\hline M2 & $50^{\circ} 28^{\prime} 12.6^{\prime \prime} \mathrm{N} ; 2^{\circ} 03^{\prime} 44.5^{\prime \prime} \mathrm{E}$ & Planquette & Surface runoff & Sediment trap & 3 Feb 2017 & & \\
\hline Cb1a & $50^{\circ} 25^{\prime} 56.3^{\prime \prime} \mathrm{N} ; 2^{\circ} 02^{\prime} 05.0^{\prime \prime} \mathrm{E}$ & Planquette & Channel bank & PVC pipe & 3 Feb 2017 & & \\
\hline Cb1b & $50^{\circ} 25^{\prime} 56.3^{\prime \prime} \mathrm{N} ; 2^{\circ} 02^{\prime} 05.0^{\prime \prime}$ & Planquette & Channel bank & PVC pipe & 3 Feb 2017 & & \\
\hline $\mathrm{Cb} 2 \mathrm{a}$ & $50^{\circ} 24^{\prime} 26.0^{\prime \prime} \mathrm{N} ; 1^{\circ} 58^{\prime} 11.0^{\prime \prime} \mathrm{E}$ & Planquette & Channel bank & PVC pipe & 3 Feb 2017 & & \\
\hline $\mathrm{Cb} 2 \mathrm{~b}$ & $50^{\circ} 24^{\prime} 26.0^{\prime \prime} \mathrm{N} ; 1^{\circ} 58^{\prime} 11.0^{\prime \prime} \mathrm{E}$ & Planquette & Channel bank & PVC pipe & 3 Feb 2017 & & \\
\hline Cb3a & $50^{\circ} 24^{\prime} 45.5^{\prime \prime} \mathrm{N} ; 1^{\circ} 55^{\prime} 43.3^{\prime \prime} \mathrm{E}$ & Canche & Channel bank & PVC pipe & 3 Feb 2017 & & \\
\hline $\mathrm{Cb} 3 \mathrm{~b}$ & $50^{\circ} 24^{\prime} 45.5^{\prime \prime} \mathrm{N} ; 1^{\circ} 55^{\prime} 43.3^{\prime \prime} \mathrm{E}$ & Canche & Channel bank & PVC pipe & 3 Feb 2017 & & \\
\hline $\mathrm{Rb} 1$ & $50^{\circ} 25^{\prime} 56.3^{\prime \prime} \mathrm{N} ; 2^{\circ} 02^{\prime} 05.0^{\prime \prime} \mathrm{E}$ & Planquette & River bed & Grab sampler & 3 Feb 2017 & & \\
\hline $\mathrm{Rb} 2$ & $50^{\circ} 24^{\prime} 26.0^{\prime \prime} \mathrm{N} ; 1^{\circ} 58^{\prime} 11.0^{\prime \prime} \mathrm{E}$ & Planquette & River bed & Grab sampler & 3 Feb 2017 & & \\
\hline $\mathrm{Rb} 3$ & $50^{\circ} 24^{\prime} 45.5^{\prime \prime} \mathrm{N} ; 1^{\circ} 55^{\prime} 43.3^{\prime \prime} \mathrm{E}$ & Canche & River bed & Grab sampler & 3 Feb 2017 & & \\
\hline $\mathrm{C} 2$ & $50^{\circ} 24^{\prime} 45.5^{\prime \prime} \mathrm{N} ; 1^{\circ} 55^{\prime} 43.3^{\prime \prime} \mathrm{E}$ & Canche & Suspended matter & Sediment trap & & 3 Feb 2017 & 6 Feb 2017 \\
\hline T3a & $50^{\circ} 24^{\prime} 26.0^{\prime \prime} \mathrm{N} ; 1^{\circ} 58^{\prime} 11.0^{\prime \prime} \mathrm{E}$ & Planquette & Suspended matter & Sediment trap & & 3 Feb 2017 & 6 Feb 2017 \\
\hline $\mathrm{T} 3 \mathrm{~b}$ & $50^{\circ} 24^{\prime} 26.0^{\prime \prime} \mathrm{N} ; 1^{\circ} 58^{\prime} 11.0^{\prime \prime} \mathrm{E}$ & Planquette & Suspended matter & Sediment trap & & 3 Feb 2017 & 6 Feb 2017 \\
\hline $\mathrm{T} 3 \mathrm{c}$ & $50^{\circ} 24^{\prime} 26.0^{\prime \prime} \mathrm{N} ; 1^{\circ} 58^{\prime} 11.0^{\prime \prime} \mathrm{E}$ & Planquette & Suspended matter & Sediment trap & & 3 Feb 2017 & 6 Feb 2017 \\
\hline T3d & $50^{\circ} 24^{\prime} 26.0^{\prime \prime} \mathrm{N} ; 1^{\circ} 58^{\prime} 11.0^{\prime \prime} \mathrm{E}$ & Planquette & Suspended matter & Sediment trap & & 3 Feb 2017 & 6 Feb 2017 \\
\hline T3'a & $50^{\circ} 25^{\prime} 56.3^{\prime \prime} \mathrm{N} ; 2^{\circ} 02^{\prime} 05.0^{\prime \prime} \mathrm{E}$ & Planquette & Suspended matter & Sediment trap & & 3 Feb 2017 & 6 Feb 2017 \\
\hline $\mathrm{T} 3 \mathrm{z}^{\prime} \mathrm{b}$ & $50^{\circ} 25^{\prime} 56.3^{\prime \prime} \mathrm{N} ; 2^{\circ} 02^{\prime} 05.0^{\prime \prime} \mathrm{E}$ & Planquette & Suspended matter & Sediment trap & & 3 Feb 2017 & 6 Feb 2017 \\
\hline T3' c & $50^{\circ} 25^{\prime} 56.3^{\prime \prime} \mathrm{N} ; 2^{\circ} 02^{\prime} 05.0^{\prime \prime} \mathrm{E}$ & Planquette & Suspended matter & Sediment trap & & 3 Feb 2017 & 6 Feb 2017 \\
\hline $\mathrm{T} 3{ }^{\prime} \mathrm{d}$ & $50^{\circ} 25^{\prime} 56.3^{\prime \prime} \mathrm{N} ; 2^{\circ} 02^{\prime} 05.0^{\prime \prime} \mathrm{E}$ & Planquette & Suspended matter & Sediment trap & & 3 Feb 2017 & 6 Feb 2017 \\
\hline samples 1 to 24 & $50^{\circ} 28^{\prime} 43.7^{\prime \prime} \mathrm{N} ; 1^{\circ} 44^{\prime} 54.3^{\prime \prime} \mathrm{E}$ & Canche & Suspended matter & Automatic sampler & & 8 Jun 2016 19:30 & 11 Jun 2016 16:30 \\
\hline
\end{tabular}

topsoils B-horizon material were collected in February 2017 at three different locations: two within the Planquette River catchment ( $\mathrm{Cb} 1$ and $\mathrm{Cb} 2)$ and one within the Canche River catchment (Cb3; Figure 1c). At each location, one sample was collected above the water table (Cb1a, Cb2a, and $\mathrm{Cb} 3 \mathrm{a})$ and a second below the water table $(\mathrm{Cb} 1 \mathrm{~b}, \mathrm{Cb} 2 \mathrm{~b}$, and $\mathrm{Cb} 3 \mathrm{~b})$ by pushing a $5-\mathrm{cm}$ diameter PVC pipe about $10 \mathrm{~cm}$ into the channel bank face (Figure 2). River bed sediment samples (Rb1, Rb2, and Rb3) were also collected at the above described three sites using a $2.4 \mathrm{~L}$ zinc-plated heavy steel benthic grab sampler (Figure 2, Table 2). The benthic grab sampler is deployed at the midpoint of the channel's width. At a given location, three grabs are recovered, each rendering between 100 and $300 \mathrm{~g}$ of sediment, and mixed. Both the channel bank and river bed sediments were sampled 1 day before the start of the winter 2017 flood event. In total 11 SPM, 6 channel bank, and 3 river bed samples were taken during the winter 2017 flood event (Table 2).

The 119 samples analyzed in this study are listed in Tables 1 and 2 and sampling specifications (method, period, location) summarized. Supporting information Table S9 lists a selection of topsoil samples from the Canche River catchment previously studied by Patault (2018) and used in the present study.

In the laboratory, collected SPM samples were passed through a flow-through centrifuge (Ultra centrifuge Beckman Coulter optimal L $90 \mathrm{~K}$; flow rate $=18,000 \mathrm{rpm}$ during $15 \mathrm{~min}$ ) to separate water from the solid fraction. The supernatant was filtered using cellulose nitrate filters $(0.45 \mu \mathrm{m}$ pore size $)$ to check for any sediment residuals. The SPM recovered after centrifugation and all other sediment samples were sieved with a $2 \mathrm{~mm}$ mesh to remove coarse debris and macro organics. Sieved samples were then dried for $72 \mathrm{hr}$ in an oven at $30{ }^{\circ} \mathrm{C}$.

Weather conditions show temporal variability between the different sampling campaigns (sc; Figure 4). For sc1 (winter 2015), rainfall amount was measured at $24.5 \mathrm{~mm}$ at Radinghem and $17.2 \mathrm{~mm}$ at Touquet-Paris-Plage. The mean discharge of the Canche River was $26 \mathrm{~m}^{3} \mathrm{~s}^{-1}$. For the second campaign (sc2) in winter 2016, rainfall amount was estimated at 6.8 and $12.3 \mathrm{~mm}$, respectively at the same reference stations and a mean flow discharge of $25 \mathrm{~m}^{3} \mathrm{~s}^{-1}$ for the Canche River. During sc2, three sediment traps were vandalized (T2, C3, C5), new traps immediately redeployed and sampled the following week. Rainfall was higher during the second week with 61 and $42.2 \mathrm{~mm}$ recorded at Radinghem and Touquet-Paris-Plage, respectively. For sc3 (spring 2016), the amount of rainfall was relatively high (33.7 and $23.8 \mathrm{~mm}$, respectively), yet the mean discharge in the Canche River was lower $\left(19 \mathrm{~m}^{3} \mathrm{~s}^{-1}\right)$. One trap (C1) was resampled 


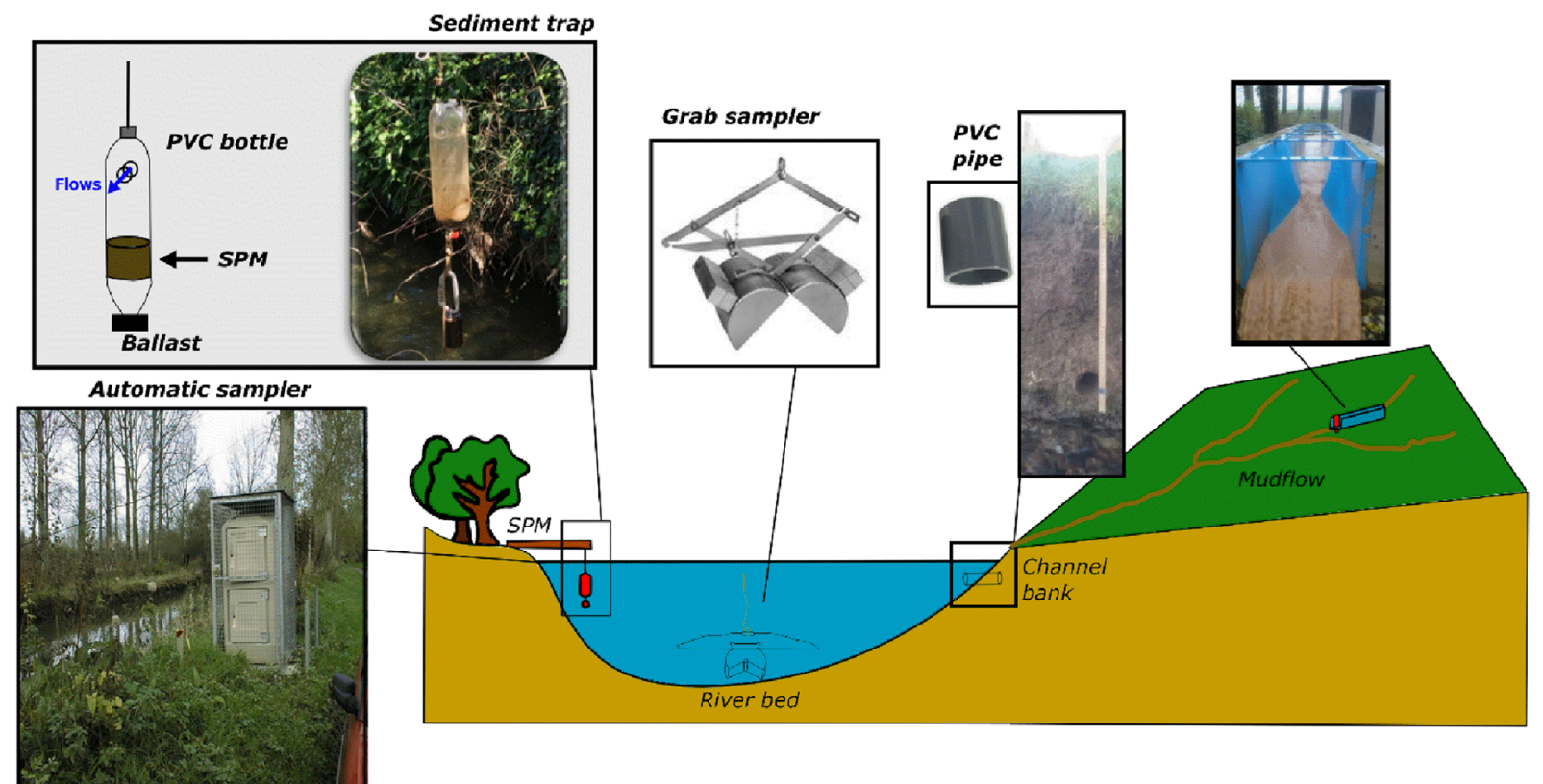

Figure 2. Experimental devices used to sample the different sediments of this study.

due to vandalism the following week during which the rainfall amount was 15.1 and $7.8 \mathrm{~mm}$ at Radinghem and Touquet-Paris-Plage, respectively. During the fourth campaign (sc4) in summer 2016, the rainfall amount was significantly different between the two stations with $43.3 \mathrm{~mm}$ at Radinghem and $6 \mathrm{~mm}$ at Touquet-Paris-Plage due to very localized precipitations. Three traps were resampled the following week (C1, C2, and C6) during which both stations received $50 \mathrm{~mm}$ of rainfall. For the last sampling campaign (sc5) in autumn 2016, both rainfall reference stations received $30 \mathrm{~mm}$ and the Canche River flow discharge was relatively low $\left(14 \mathrm{~m}^{3} \mathrm{~s}^{-1}\right)$. For the two specific flood events occurring between $8-11$ June 2016 (fe1) and 3-6 February 2017 (fe2), the rainfall amount was quantified at 36 and $30 \mathrm{~mm}$, respectively.

\subsection{Laboratory Methods}

\subsubsection{Room Temperature Magnetic Measurements (Magnetic Hysteresis Loops)}

Magnetic properties were obtained from hysteresis loops using an alternating gradient force magnetometer (AGFM 2900) at the Laboratoire des Sciences du Climat et de l'Environnement (LSCE). Hysteresis loops were measured at room temperature on 2 to $25 \mathrm{mg}$ of dried and sieved bulk sediments (see section 2.3) by cycling the field to maximum applied field of $\pm 0.3 \mathrm{~T}$ (first low-field loop), and subsequently between $\pm 1 \mathrm{~T}$ (high-field loop) both at a $10 \mathrm{mT}$ step resolution. For the SPM samples, one to three subsamples were analyzed depending on the sample mass available.

Magnetic parameters derived from the high-field (1 T) slope corrected hysteresis loop data are as follows: saturation magnetization $\left(M_{\mathrm{s}}\right)$, saturation remanent magnetization $\left(M_{\mathrm{rs}}\right)$, and coercive force $\left(H_{\mathrm{c}}\right)$. In a separate experiment, a stepwise increasing backfield (max. field $1 \mathrm{~T}$ ) is applied to $M_{\mathrm{rs}}$ to determine the remanent
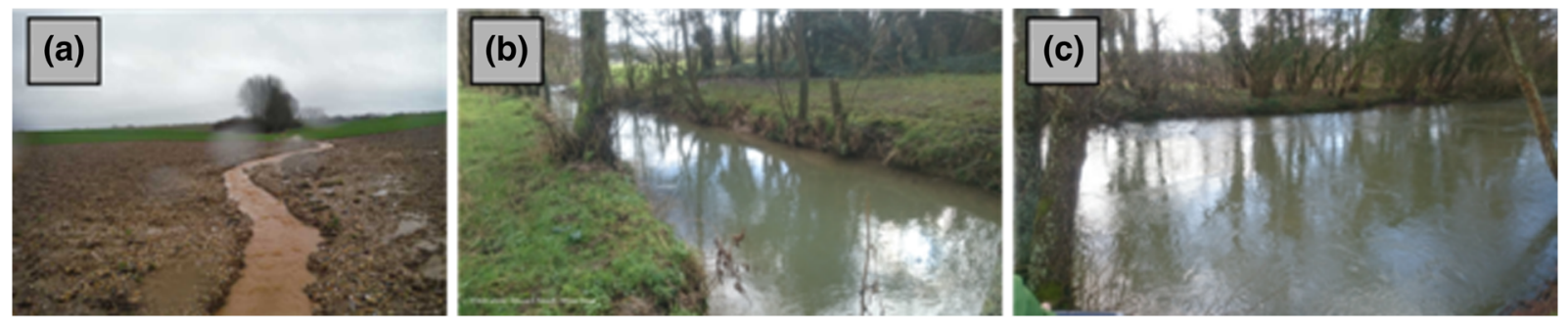

Figure 3. (a) Surface runoff in the upstream part of the Planquette catchment, picture (a) was taken during a typical flood event, (b) the Planquette River at site T3, and (c) the Canche River at site C2; photos (b) and (c) were taken during intermediate water conditions. 


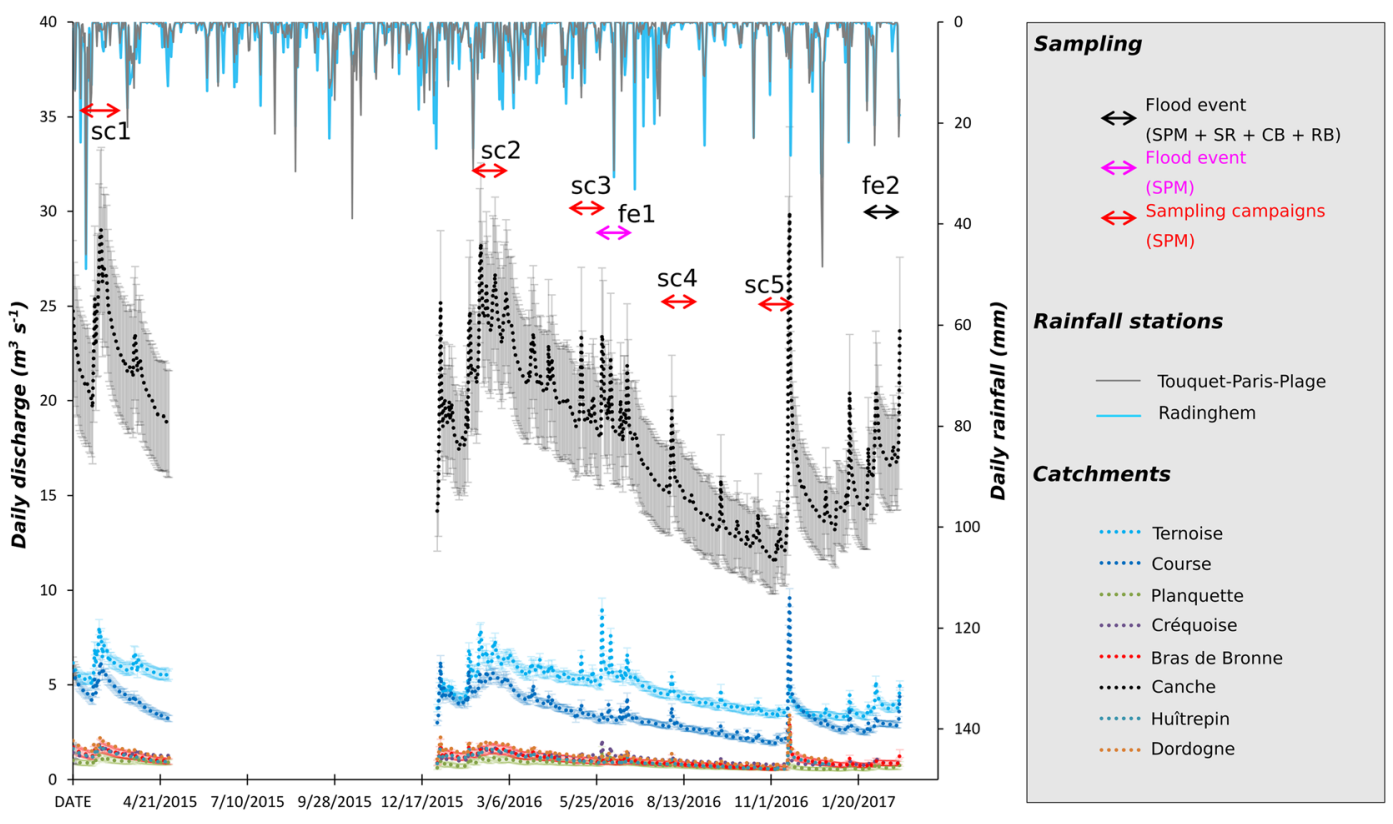

Figure 4. Daily discharge $\left(\mathrm{m}^{3} \mathrm{~s}^{-1}\right)$ and daily rainfall $(\mathrm{mm})$ in the Canche River catchment and its tributaries during the different sampling campaigns. (Acronyms: Suspended particulate matter (SPM); surface runoff (SR); channel bank $(\mathrm{Cb})$; river bed $(\mathrm{Rb}))$.

coercive force $\left(H_{\mathrm{cr}}\right) \cdot M_{\mathrm{s}}$ and $M_{\mathrm{rs}}$ values are normalized to the sample mass. The $S$ ratio is calculated according to the equation proposed by King and Channell (1991):

$$
\text { Sratio }=-{ }^{-I R M_{0.3 T}} / \operatorname{SIRM}_{1 T}
$$

The alternating gradient magnetometer is known to be very sensitive to the mass of the sample (Shah \& Wakai, 2013). To ensure that there is no major bias in our magnetic hysteresis data and that our samples are representative of the respective SPM obtained in the traps, we compared the results of four different seasonal samples from site C2 obtained on the alternating gradient force magnetometer AGFM 2900 at the LSCE to the magnetic hysteresis parameters obtained using a Vibrating Sample Magnetometer (VSM) at the Institut de Physique du Globe de Paris (IPGP), which has a maximum applied field of $1.8 \mathrm{~T}$, dictated by the pole spacing and enables the analysis of larger sample masses (about 200 to $350 \mathrm{mg}$ of SPM). For each tested samples, the single VSM measurement falls within the error bar of the multiple aliquots (3 to 5) AGFM measurements (Figure S1 in the supporting information). The discrepancy between the VSM and the mean AGFM values lies between $4.5 \%$ and $26 \%$ of the standard deviation error, with exception of sample C2 autumn 2016, where it is $42 \%$. Thus, the AGFM data, despite being acquired on a few milligrams may be considered representative of a larger sample mass.

\subsection{Decomposition of IRM Components}

The analysis of isothermal remanent magnetization (IRM) acquisition curves based on Cumulative Log Gaussian (CLG) analysis was first proposed by Robertson and France (1994) to discriminate remanence-carrying minerals in mixtures. Later, Kruiver et al. (2001) demonstrated that magnetic coercivity distributions could be determined based on the CLG appearance of isothermal remanent magnetization (IRM) acquisition curves even if acquisition is far from saturation. A typical example of IRM acquisition curve is shown in Figure S2 of the supporting information. Many approached have been proposed to unmix IRM acquisition curves (see review by Heslop, 2015), in the present study we used the approach described in Kruiver et al. (2001).

The IRM curve is decomposed into several CLG curves, which can be individually characterized by (i) their saturated isothermal remanent magnetization (SIRM), (ii) their mean coercivity $\left(H_{1 / 2}\right)$ and (iii) their dispersion parameter. The CLG analysis is realized with the model used by Kruiver et al. (2001) in an Excel 
worksheet (http://www.geo.uu.nl/ forth/). Three different representations from the IRM acquisition curve can be plotted. Initial values for SIRM, $H_{1 / 2}$ and dispersion parameter are estimated from the Linear Acquisition Plot (LAP), the Gradient of Acquisition Plot (GAP), and the Standardized Acquisition Plot (SAP) respectively. LAP referred to the analysis of IRM curves on a linear ordinate scale, GAP as the gradient curve, and SAP as the probability scale.

\subsection{Thermomagnetic Measurements}

Room temperature saturation isothermal remanent magnetization (RT-SIRM) experiments were performed on dry bulk sediments using the Quantum Design XL-5 EverCool Magnetic Properties Measurement System (MPMS; noise level $\sim 10-11 \mathrm{Am}^{2}$ ) housed at the IPGP. A $2.5 \mathrm{~T}$ field was applied at room temperature (RT), subsequently the sample was cycled from 300 to $10 \mathrm{~K}$ (cooling) and back to $300 \mathrm{~K}$ (warming) at a $5 \mathrm{~K} \mathrm{~min}^{-1}$ sweep rate in zero field, and the remanent magnetization monitored at $5 \mathrm{~K}$ increments.

Low-temperature (LT) SIRM after zero-field cooled (ZFC) and field-cooled (FC) pretreatments from 400 to $10 \mathrm{~K}$ were acquired at $10 \mathrm{~K}$. The ZFC and FC LT-SIRM are monitored at a $5 \mathrm{~K}$ increments upon warming from $10-400 \mathrm{~K}$ at a $5 \mathrm{~K} \mathrm{~min}^{-1}$ sweep rate.

To obtain further knowledge on the individual magnetic components present in the natural mixture of the SPM and sediment samples, a recently proposed experimental protocol (Lagroix \& Guyodo, 2017), was applied on four selected samples from sample site C2. It begins with a classic RT-SIRM experiment as described above (i.e., a $2.5 \mathrm{~T}$ IRM acquired at $300 \mathrm{~K}$ is monitored while cycling the temperature from 300 to $10 \mathrm{~K}$ and back to $300 \mathrm{~K}$ ). A $2.5 \mathrm{~T}$ field is then applied as the sample is warmed to $400 \mathrm{~K}$ and cooled back to $300 \mathrm{~K}$ resulting in an "enhanced” RT-SIRM. Lagroix and Guyodo (2017) state that if any goethite is present in the sample, the "enhanced" RT-SIRM pretreatment will result in goethite acquiring a thermoremanent magnetization (TRM) as the sample cools in the presence of a magnetic field through the Néel temperature for stoichiometric goethite (393 K; Ozdemir \& Dunlop, 1996).

The enhanced RT-SIRM is monitored while cycling the temperature from 300 to $10 \mathrm{~K}$ and back to $300 \mathrm{~K}$. Subsequently, the cycled "enhanced" RT-SIRM is partially demagnetized by exposing the sample to a decreasing oscillating field from a peak field of $0.3 \mathrm{~T}$ to zero. Low coercivity remanences removed, the remaining remanent magnetization is monitored while cycling temperatures from 300 to $10 \mathrm{~K}$ and back to $400 \mathrm{~K}$. Finally, the remaining remanent magnetization is cycled one last time from 400 to $10 \mathrm{~K}$ and back to $300 \mathrm{~K}$. Throughout, temperature sweep rate is kept constant at $5 \mathrm{~K} \mathrm{~min}^{-1}$ and measurement interval constant at $5 \mathrm{~K}$.

\section{Results}

\subsection{Identification of the Magnetic Carriers}

\subsubsection{LT Magnetic Behavior (MPMS Experiments)}

LT warming curves of ZFC and FC remanence (Figure 5) before and after demagnetization from a peak field of $300 \mathrm{mT}$ of the LT-SIRM show a sharp drop in remanence between 10 and $30 \mathrm{~K}$ corresponding to the presence of ultrafine-grained (3-5 nm) superparamagnetic phase (Guyodo et al., 2003, 2006; Özdemir et al., 1993). The Verwey transition observed at $\sim 110 \mathrm{~K}$ in the nondemagnetized warming curves (Figure 5, solid lines) indicates the presence of slightly oxidized magnetite (Kosterov, 2003; Özdemir et al., 2002). The demagnetized LT-SIRM ZFC and FC warming curves (Figure 5, dashed lines) show no signs of a Verwey transition. From the difference in remanence loss before and after demagnetization, we can deduce that the remanence fraction carried by low-coercivity minerals is greater in winter and spring 2016 at site C2 than in summer and autumn 2016 at the same site. The difference between the ZFC and FC curves, which persists in all curves and is even accentuated in the demagnetized LT-SIRM warming, attest to the presence of high-coercivity minerals and is characteristic of nanocrystalline goethite (Guyodo et al., 2003).

Figures 6a-6d (first column) show the RT-SIRM results for site C2 in the Canche River for all sampled seasons in 2016. The "classic" and "enhanced" RT-SIRM curves show a Verwey transition on cooling characteristic of magnetite (Kosterov, 2003; Özdemir et al., 2002). All curves show a continuous increase of remanence with decreasing temperature throughout the entire measurement range, which is accentuated in the "enhanced" RT-SIRM. This behavior can be attributed to the presence of goethite (Dekkers, 1989; Lowrie 

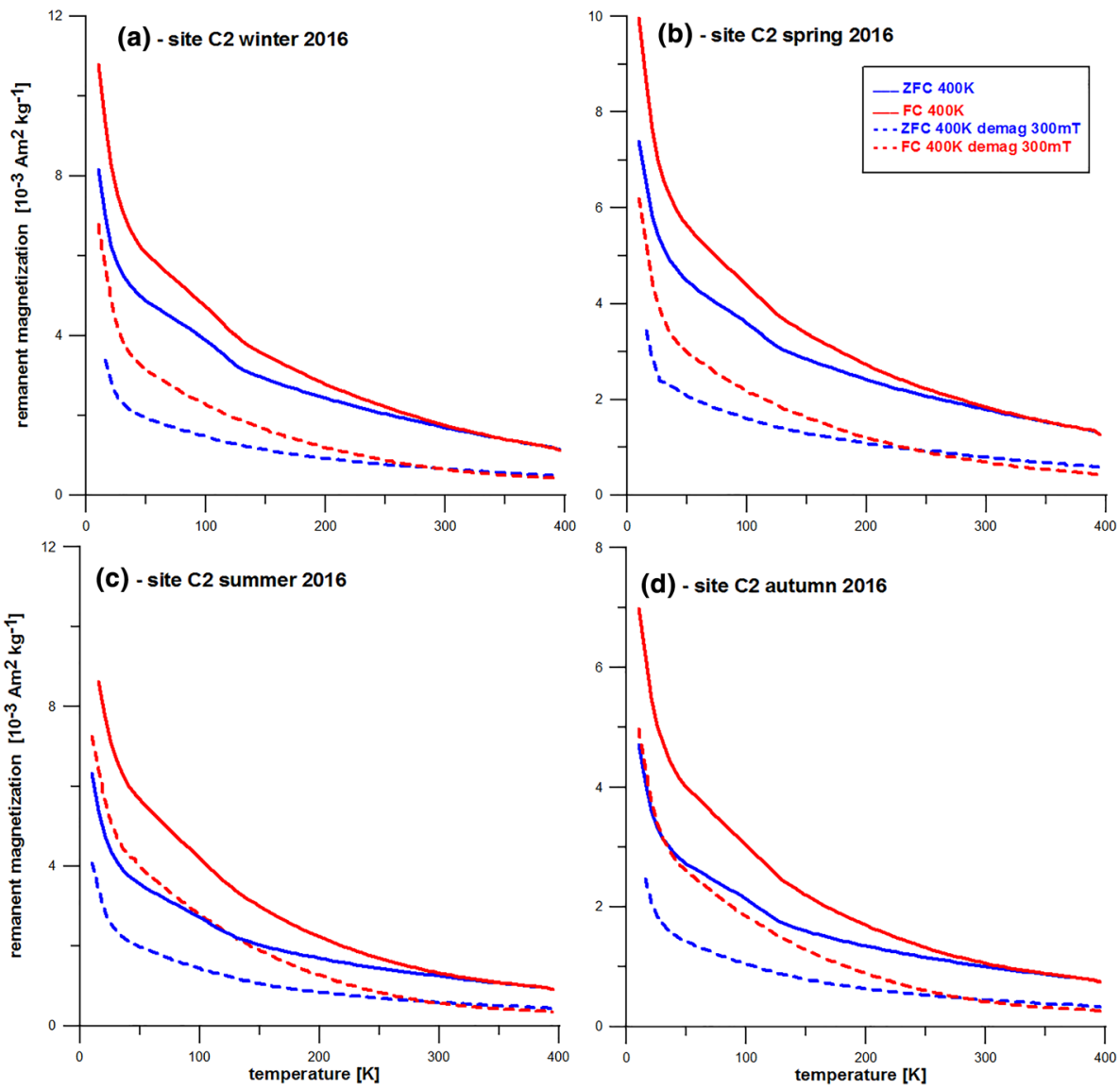

Figure 5. Low-temperature SIRM acquired at $10 \mathrm{~K}$ in a $2.5 \mathrm{~T}$ field warming curves after zero-field cooling (ZFC; blue solid line) and $2.5 \mathrm{~T}$ field cooling (FC; red solid line) from 400 to $10 \mathrm{~K}$ of four selected seasonal SPM samples (panels a to d) from site C2 (Canche River downstream confluence Planquette River) compared to the remaining ZFC and FC LT-SIRM after demagnetization over the 0 to $300 \mathrm{mT}$ window (same color code, dashed lines) following the protocol in Lagroix and Guyodo (2017).

\& Heller, 1982). The cooling and warming cycles are reversible in the 10 to $100 \mathrm{~K}$ temperature range except for the spring 2016 sample which is reversible only in the 10 to $70 \mathrm{~K}$ range.

Comparison of the classic and enhanced RT-SIRM cycles (Figures 6a-6d, first column) with the demagnetized enhanced RT-SIRM (Figures 6e-6h, second column) show the successful elimination of the (dominant) magnetite component using the protocol proposed by Lagroix and Guyodo (2017). This is particularly helpful for the identification of the presumed remaining high-coercivity carriers, such as goethite and hematite. The resulting first cooling-warming cycle (between 300 to $10 \mathrm{~K}$ and back to $400 \mathrm{~K}$ ) of the enhanced then $0.3 \mathrm{~T}$ demagnetized RT-SIRM clearly shows a steadily increasing goethite-dominated signal that is perfectly reversible in the summer and autumn 2016 samples and shows a slight irreversibility above $100 \mathrm{~K}$ in the winter and spring 2016 samples. The slight irreversible behavior is likely due to partially oxidized magnetite, which was not demagnetized by the $0.3 \mathrm{~T}$ peak oscillating field. The remanence loss on heating to $400 \mathrm{~K}$ could result from the thermal demagnetization of goethite as it is heated above its Néel temperature (393 K). Another possible source of remanence loss between 300 and $400 \mathrm{~K}$ could be the unblocking of superparamagnetic particles that are likely to be present in the samples.

The zooms of the second run (Figures 6i-61, third column) corresponding to the enhanced $0.3 \mathrm{~T}$ peak oscillating field demagnetized and thermal-demagnetized RT-SIRM display magnetizations that increase with decreasing temperature and reversible in the summer and spring $\mathrm{C} 2$ samples. The winter sample displays an even smaller irreversibility in the 100 to $300 \mathrm{~K}$ range, while the spring sample displays a small but 

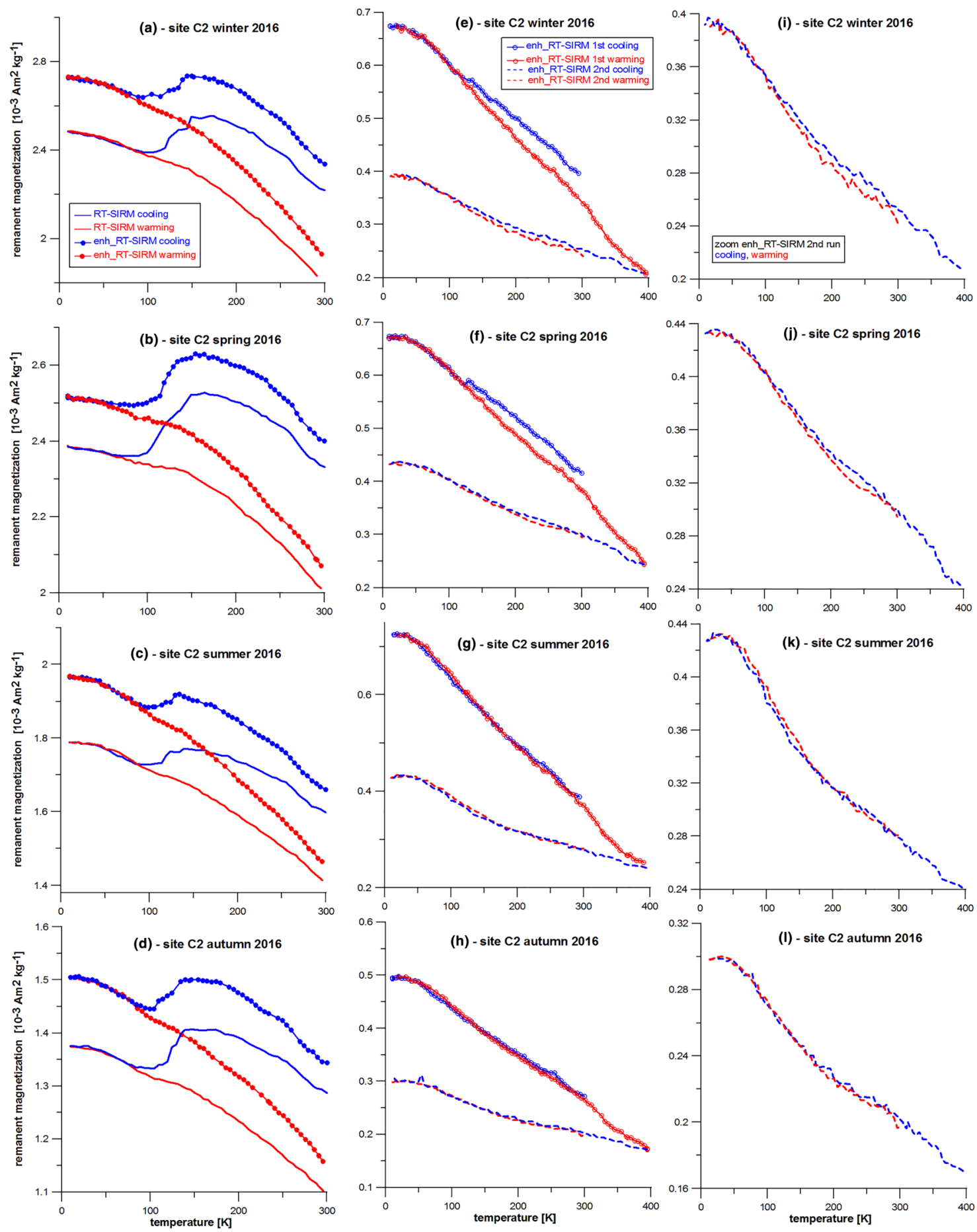

Figure 6. Cooling and warming cycle of a room temperature saturation isothermal remanent magnetization (RT-SIRM) acquired in a $2.5 \mathrm{~T}$ field at $300 \mathrm{~K}$ (solid lines in a-d) for four selected seasonal SPM samples from site C2 (Canche River downstream confluence Planquette River) and an enhanced RT-SIRM acquired by exposing the sample to a $2.5 \mathrm{~T}$ field over the 300 to $400 \mathrm{~K}$ temperature range prior to cooling-warming cycle (closed circles in a-d). Plots (e) through (h) show the cycling of the remaining enhanced RT-SIRM after demagnetization over the $0-300 \mathrm{mT}$ field window (open circles) and further thermal demagnetization by heating to $400 \mathrm{~K}$ (dashed lines). Plots (i) through (l) are a zoomed view of the enhanced RT-SIRM after both $300 \mathrm{mT}$ and thermal demagnetization. The measurement protocol follows Lagroix and Guyodo (2017). 


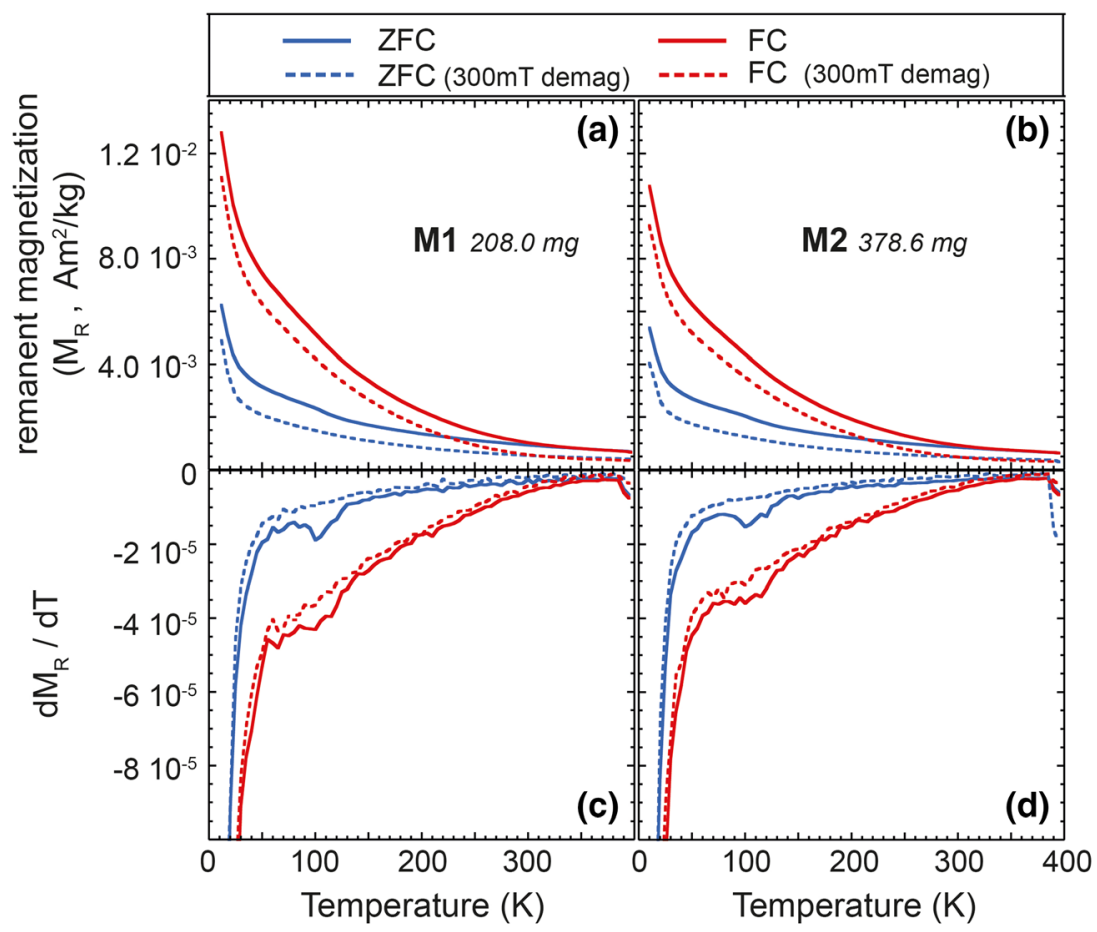

Figure 7. Low-temperature SIRM acquired at $10 \mathrm{~K}$ in a $2.5 \mathrm{~T}$ field warming curves after zero-field cooling (ZFC; blue solid line) and field cooling (FC; red solid line) of two surface runoff samples M1 (panel a) and M2 (panel b) samples from the Venturi channel, Pommeroye River (see section 2.3) compared to the remaining ZFC and FC LT-SIRM after demagnetization over the 0 to $300 \mathrm{mT}$ window (same color code, dashed lines) following the protocol in Lagroix and Guyodo (2017). Panels (c) and (d) show the first derivatives of the respective curves shown in the panels above (using the same color code) to highlight the mentioned temperature (Verwey) transitions.

perceptible thermal hysteresis between 190 and $270 \mathrm{~K}$, which may be the result of hematite's Morin transition.

The same MPMS measurement protocol was applied to the surface runoff samples from the Pommeroye River, which originate from the runoff eroding the topsoils A-horizon during the winter 2017 rain event. The LT ZFC and FC warming curves (Figure 7) before and after demagnetization in a $300 \mathrm{mT}$ field show all the same features as in the SPM samples of site C2. Intensities most resemble those of the winter 2016 SPM at C2 (Figure 5a) but the Verwey transition prior de demagnetization is much less prominent and the amount of magnetization lost after demagnetization is significantly less in the surface runoff samples than the winter SPM, resembling more the summer 2016 SPM sample (Figure 5c).

The RT-SIRM series of cooling and warming cycles of the surface runoff samples (Figure 8) show very similar results observed for the SPM samples of site C2 (Figure 6), with the remanent magnetization increasing steadily as temperature decreases, a total remanence loss through the Verwey transition of about $10 \%$ (similar to the summer $2016 \mathrm{C} 2$ site sample, Figure 6) and almost perfect reversibility after demagnetization in $300 \mathrm{mT}$ oscillating field. The last cooling and warming cycle of M2 displays slight irreversibility (or thermal hysteresis) between 150 and $300 \mathrm{~K}$, which may be an expression of the hematite's Morin transition.

Lastly, a representative topsoil sample (CAN3) from the Planquette River catchment was analyzed following the above described MPMS protocols, as well as coarser and finer than $200 \mu \mathrm{m}$ separates of the bulk CAN3. The source of the SPM is postulated to be the topsoil; the data acquired on CAN3 and its separated grain size fractions provides means to test the postulate. The series of ZFC, FC, and RT-SIRM experiments (Figures S3 to S5) display the same temperature dependent behavior as in the SPM and surface runoff samples from which a magnetic mineral assemblage of goethite, magnetite and possibly hematite is evidenced. 

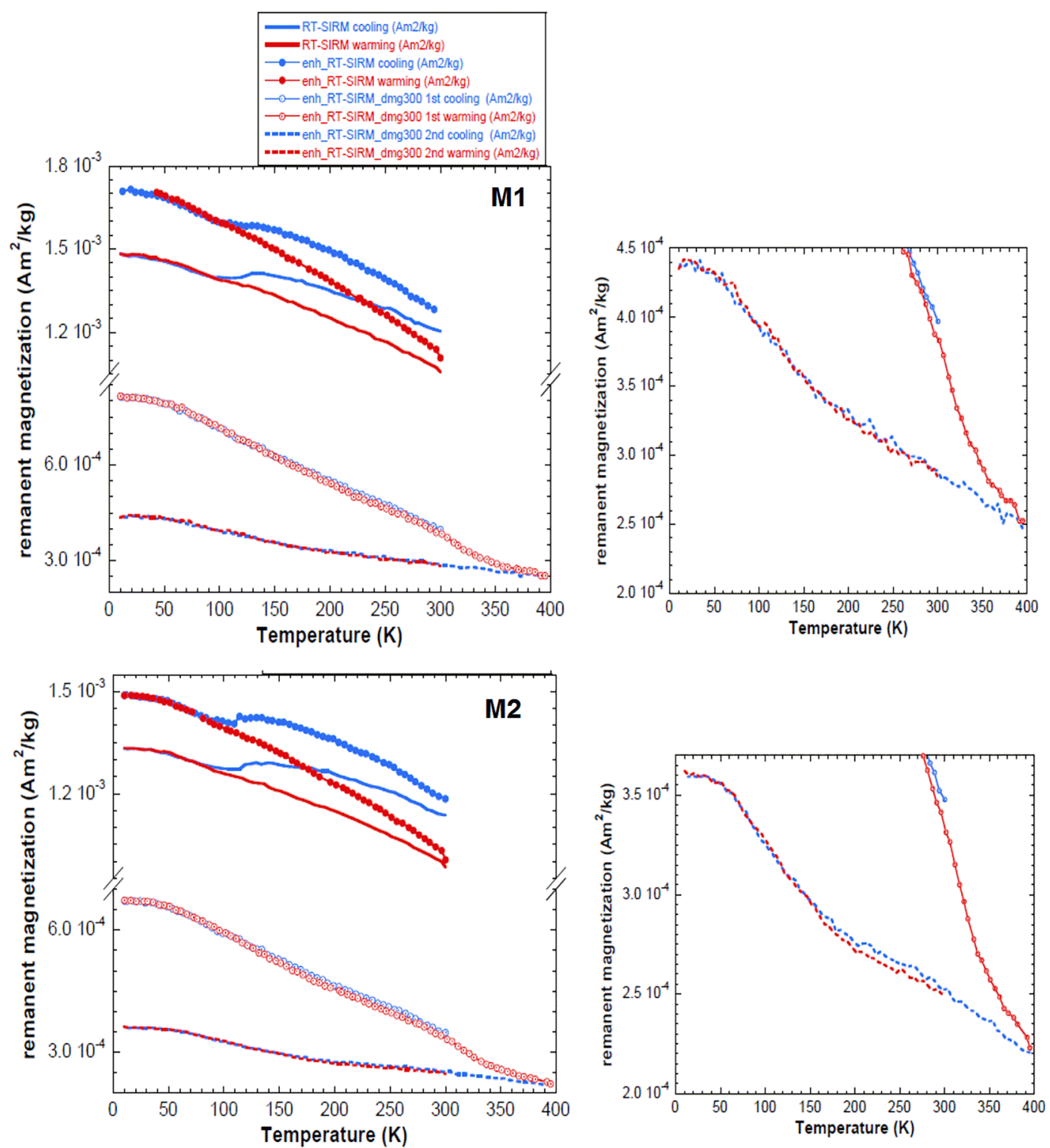

Figure 8. Cooling and warming cycle of RT-SIRM acquired in a $2.5 \mathrm{~T}$ field at $300 \mathrm{~K}$ (solid lines) and an enhanced RT-SIRM acquired by exposing the sample to a $2.5 \mathrm{~T}$ field over the 300 to $400 \mathrm{~K}$ temperature range prior to cooling-warming cycle (filled circles) for the surface runoff samples M1 and M2. Cycling of the enhanced RT-SIRM remaining after demagnetization over the 0-300 $\mathrm{mT}$ field window (open circles) and further thermal demagnetization by heating to $400 \mathrm{~K}$ (dashed lines) are plotted. The right-hand panels show the respective zoomed views of the last cycle (remaining enhanced RT-SIRM after both $300 \mathrm{mT}$ and thermal demagnetization). The measurement protocol follows Lagroix and Guyodo (2017).

\subsubsection{RT Magnetic Hysteresis Results}

First, we focused on a restricted area of the Canche River catchment to validate our rock magnetic approach and to test certain assumptions before interpretating the large data set acquired on dry bulk samples across the Canche River watershed.

Figure 9 presents the results from the RT magnetic hysteresis analyses performed on the SPM samples collected at site $\mathrm{C} 2$ downstream of the confluence of the Planquette and the Canche rivers (see also map Figure 1). Magnetic concentration, evaluated by $M_{\mathrm{s}}$ (Figure 9a), through the five sampled seasons vary between $\sim 5$ and $30 \times 10^{-3} \mathrm{Am}^{2} \mathrm{~kg}^{-1}$ and are comparable to published values from upstream of the Seine River (Franke et al., 2009; Kayvantash, 2016) in a similar land use and lithological context (agricultural 

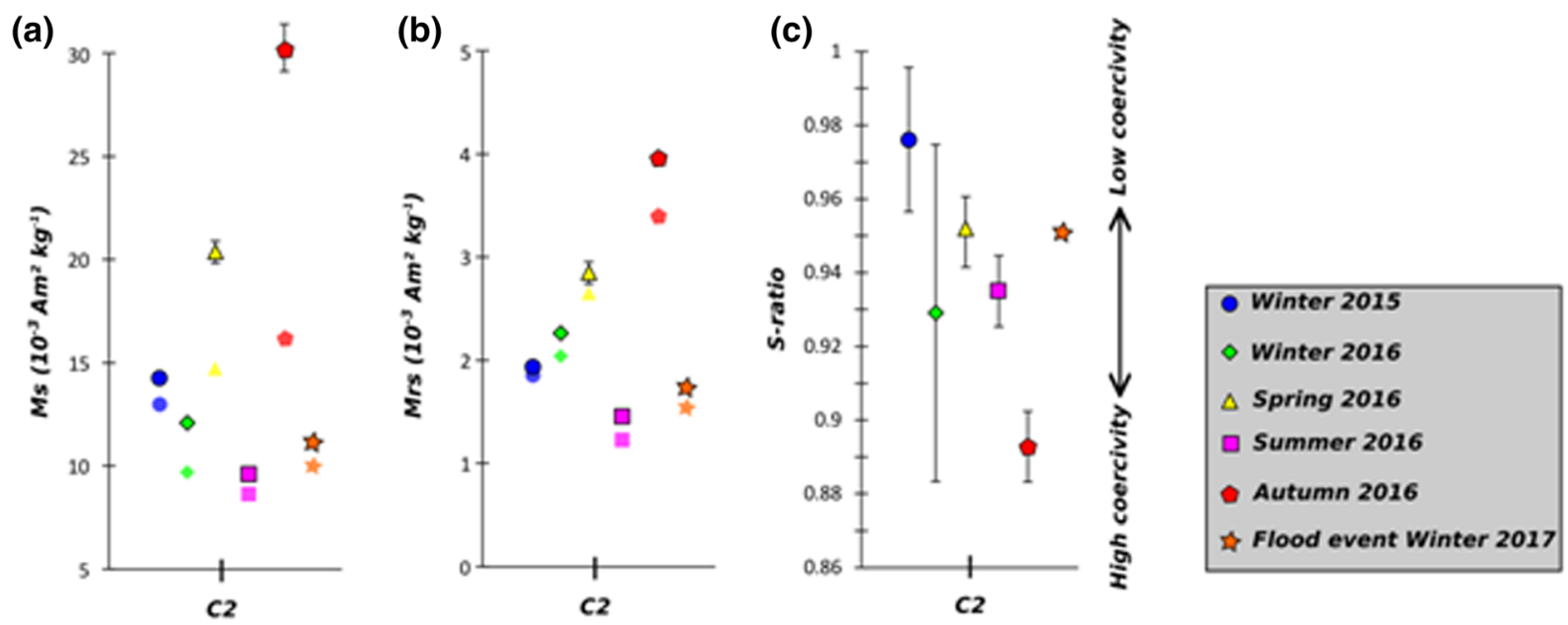

Figure 9. (a) Saturation magnetization (Ms), (b) saturation remanent magnetization (Mrs), and (c) $S$ ratio values of seasonal samples collected at site C2 in the Canche River watershed between 2015 and 2017 are presented. C2 is located just downstream from the Canche-Planquette confluence. Data derived from 0.3 and $1 \mathrm{~T}$ maximum field hysteresis loops are drawn without and with a rim, respectively.

rural area, Jurassic chalk or marls). For samples from winter 2015, summer 2016, and winter 2017, $M_{\mathrm{S}}$ values obtained from maximum field hysteresis loops of 0.3 and $1 \mathrm{~T}$ are very similar $\left(\Delta M_{\mathrm{s}}<2 \times 10^{-3} \mathrm{Am}^{2} \mathrm{~kg}^{-1}\right)$. Winter 2016 sample shows an intermediate $\Delta \mathrm{M}_{\mathrm{s}}$ of $\sim 5 \times 10^{-3} \mathrm{Am}^{2} \mathrm{~kg}^{-1}$, while spring 2016 and autumn 2016 samples show a large $\left(\Delta M_{\mathrm{s}}>5 \times 10^{-3} \mathrm{Am}^{2} \mathrm{~kg}^{-1}\right)$ difference in $M_{\mathrm{s}}$. High maximum fields enable to saturate or come closer to saturating higher coercivity minerals. The remanent magnetization derived from the 0.3 and $1 \mathrm{~T}$ maximum field hysteresis loops are much more consistent with the largest difference $\left(\sim 0.5 \times 10^{-3} \mathrm{Am}^{2} / \mathrm{kg}\right)$ shown by the autumn 2016 sample. The more consistent values obtained for $M_{\mathrm{rs}}$ may indicate that additional high-coercivity mineral phases included by probing to high fields are in part superparamagnetic at room temperature. A mineral phase in the superparamagnetic states carries no remanence (Butler \& Banerjee, 1975; Dunlop \& Özdemir, 1997).

The $S$ ratio is equal or close to one for a monomagnetic mineralogy, carried by low-coercivity magnetite. As the $S$ ratio decreases significantly from a value of 1.0 the relative proportion of high-coercivity minerals, for example, hematite or goethite increases. These minerals do not reach total saturation in an applied field of $0.3 \mathrm{~T}$ (nor in $1 \mathrm{~T}$ for goethite), thus the remanent magnetization $M_{\mathrm{rs}}$ acquired at 0.3 and at $1 \mathrm{~T}$ shows a significant difference indicative of the presence of high-coercivity magnetic minerals in the sample. Frank and Nowaczyk (2008) showed that for a bimodal mixture with magnetite and hematite, the hematite content must exceed $80 \mathrm{wt} \%$ of the magnetic fraction to become visible in the IRM acquisition curves. All samples of this study have $S$ ratios <1 (Figure 9c) corresponding to a contribution of high-coercivity minerals to $M_{\mathrm{rs}}$. Agricultural soils, which dominate the studied watershed, are well oxidized and are a major source of SPM transported by runoff surface waters to rivers. The spring 2016 and autumn 2016 samples have the highest $M_{\mathrm{rs}}$ values (Figure 9b) and $S$ ratio values are 0.95 and 0.89 , respectively (Figure 9c). These $S$ ratio values are comparable to mean values stated in Kayvantash (2016) for the upstream segment of the Seine River ( 0.92). Based on the low-temperature result the high-coercivity phase is dominated by goethite and some evidence for hematite is suggested.

\subsection{Grain Size Analysis}

Considering that the magnetic carriers are dominantly present in the fine fraction $(<200 \mu \mathrm{m})$ of the samples, supported by the low temperature remanence data acquired on the CAN3 topsoil sample (Figures S3 to S5; and section 3.1.1.), we present here a comparison of the sedimentary grain size distribution of all different sample types (SPM, surface runoff, channel bank, river bed, topsoil). The sedimentary grain size analyses were previously published in Patault (2018) and Patault, Alary, Franke, and Abriak (2019) using a Beckman Coulter LS 13320 laser particle sizer (for further details please see supporting information section). Mean values for the different sediment types are summarized in Figure S6. Patault, Alary, Franke, \& Abriak 

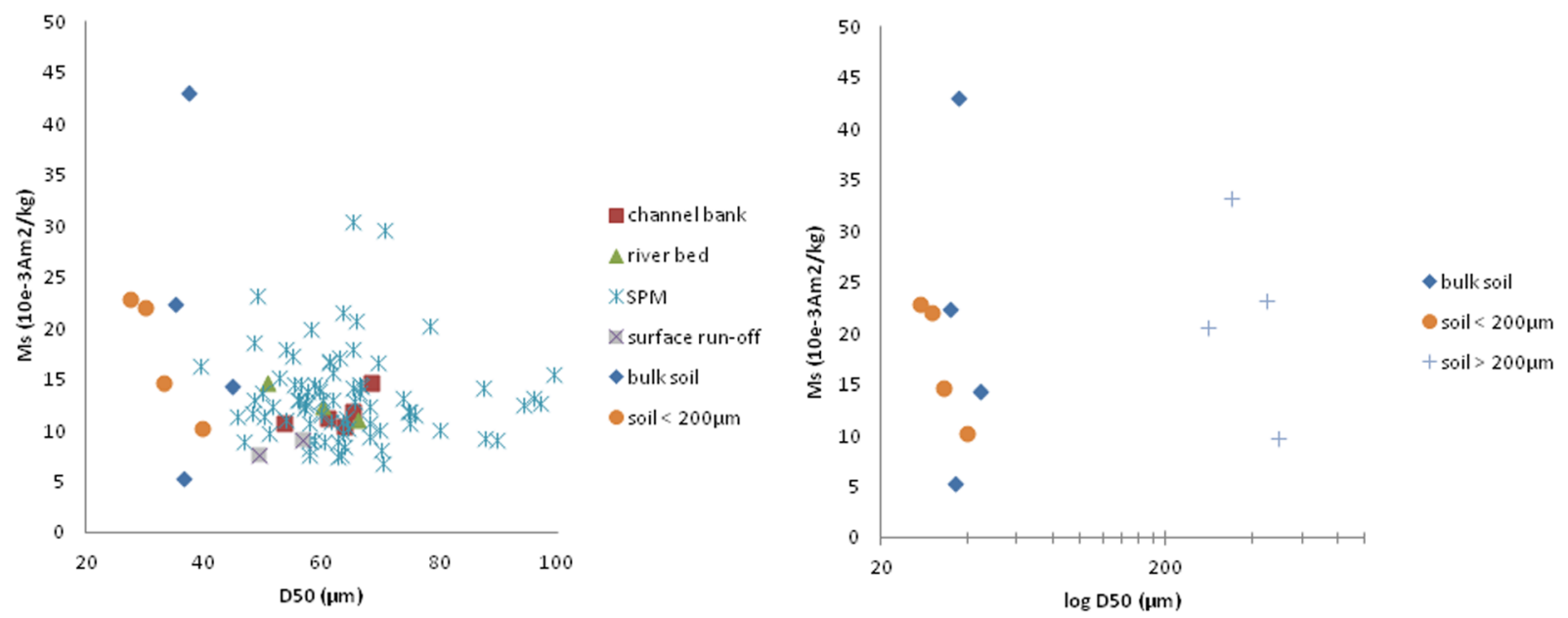

Figure 10. Comparison of D50 versus $M_{S}$ values of (a) all different sample types (SPM, channel bank, river bed, surface runoff, soil), (b) zoom on the soil samples: Bulk fraction, fine/coarse fraction of the same soil samples $>200 \mu \mathrm{m}$ fraction, $<200 \mu \mathrm{m}$ fraction, note that the $x$ axis of panel (b) is given in log scale for better visibility.

(2019)also state that the grain size (D50 median particle size values) shows no significant difference between all SPM samples taken in 2015/2016 from the Canche River and its tributaries.

Figures S7a to S7d show the comparison of the gradient of the sedimentary grain size distributions between the five different sample types of this study (SPM, channel banks, river bed, mud flow, topsoils). This comparison shows that the grain size distribution is very similar between the different sample types, but the topsoil samples have D50 values that are slightly finer (mean D50 ${ }_{\text {soil }}=38.5 \mu \mathrm{m}$ ) than the rest of the "river samples" from whatever sample type (mean D50 $\left.0_{\text {river }}=64.4 \mu \mathrm{m}\right)$.

The comparison of the SPM seasonal campaigns (Figure S7b) also shows that in general the grain size distributions are very similar, in particular between the flood event from winter 2017 and the rest of the SPM sample campaigns in 2016. There is a small exception for the SPM samples from autumn 2016 that have a slightly coarser D50 value than the rest of the SPM samples. Comparing the D50 values and grain size distribution of the SPM autumn 2016 campaign and the mean values of the river bank samples, there is a strong resemblance when regarding the mean river/water flow rate $Q_{\text {mean }}$ in Figure 14. We can see that the $\mathrm{Q}$ mean value is lowest for the autumn 2016 season. When the $Q_{\text {mean }}$ is low but the flow in the river is high, the erosion/contribution of the river bed deposit is stronger, thus the percentage of river bed particles in the water column and thus in the SPM samples increases. This is further discussed in the "seasonal mapping approach" of section 3.4.2.

In Figure 10a the sedimentary grain size distribution is compared to the respective magnetic signal of the different sample types, plotting the respective D50 value versus the $M_{\mathrm{S}}$ value (Table S9). This highlights the fact that most of the "river samples" (channel bank, river bed, surface runoff) plot well in the data cloud of the SPM samples (with some few exceptions). Surface runoff samples have slightly lower $M_{\mathrm{s}}$ values, which is likely due to the enriched composition of antiferromagnetic carriers compared to low-coercitive magnetite (compare section 3.1.1.).

To be able to compare the grain size data of the different "river samples" to those of the topsoil from the arable land, we selected representative samples from the Planquette catchment fields. In section 3.1.1., the magnetic carriers in the SPM and surface runoff samples were identified. Analyzes of the sieved fractions of the topsoil samples (Figures S3 to S5) confirmed that the majority of the magnetic carriers, in particular from the high-coercivity magnetic minerals are present in the fine grains size range $<200 \mu \mathrm{m}$. The remaining magnetic remanence of the coarser grain size fraction is mainly carried by low-coercivity magnetite.

The topsoil samples clearly plot at lower D50 values, outside the SPM data cloud, which is expected due to the grain size distribution that is mentioned above (Figures S7a to S7d). Nevertheless, the $M_{\mathrm{s}}$ values of the topsoil samples correspond very well to those of the rest of the sample set. An additional test was 


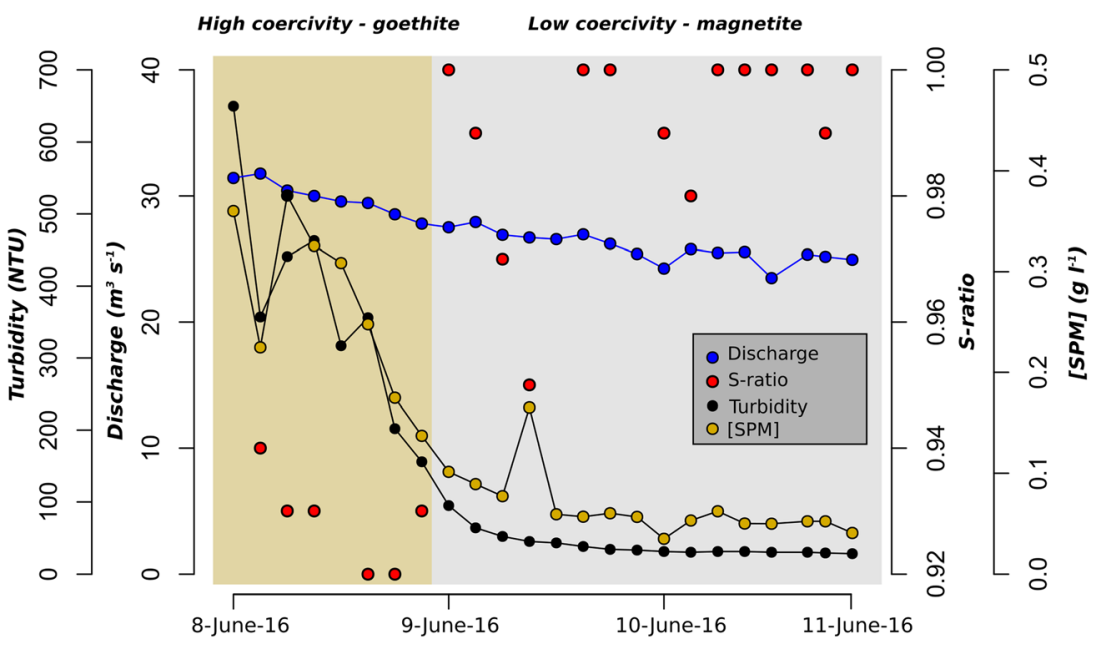

Figure 11. Comparison of the turbidity, flow discharge, $S$ ratio, and SPM concentration at the automatic sampling station in the Canche River at Attin.

performed on four topsoils from the Planquette catchment (samples PLA2, PLA4, CAN3, and CAN7; Table S9), for which the $M_{\mathrm{S}}$ values were obtained on the bulk soil and sieved coarser and finer fractions $(>200$ and $<200 \mu \mathrm{m})$. These values are given in Figure 10b; the D50 values have been theoretically recalculated for the sieved fractions and thus represent approximate values. Nevertheless, the above comparison (Figure 10) shows that the finer fraction $<200 \mu \mathrm{m}$ plots well among the bulk soil values, whereas the coarser fraction $>200 \mu \mathrm{m}$ has slightly higher $M_{\mathrm{S}}$ values, probably due to the contribution of coarse magnetite/maghemite grains present in this fraction.

\subsection{Temporal Monitoring of the $S$ Ratio During a Specific Flood Event}

The relationships between rain events, runoff/sediment particle transport and $S$ ratio are studied with the high-resolution sampling campaign performed at the Attin automated monitoring station in June 2016. Figure 11 shows the in situ turbidity of the water column compared to the $S$ ratio of the SPM samples collected during the flooding event.

The climax of the rain event occurred on 8 June 2016 at $\sim 12: 00 \mathrm{hr}$ when turbidity is highest and $S$ ratios are low, indicative of a high concentration of high-coervicity minerals. Turbidity decreases rapidly over the first $24 \mathrm{hr}$ of the rain event then slowly toward a baseline, which coincides with an abrupt increase in $S$ ratio values reaching equal or close to 1 . Between early morning and midday of 10 June 2016, the $S$ ratio drops twice reflective and increase in high-coercivity minerals in the SPM of the Canche River channel.

The relationships between the amount of suspended particles (SPM), the flow discharge and the evolution of the magnetic material in the water column of our data set are similar to those observed in Walling et al. (1979) and Slattery et al. (1995). The authors deduced from the coercivity profiles that the sampled storm material originated from cultivated topsoil sources. Likewise, we interpret low $S$ ratios as tracing high-coervivity minerals originating from runoff induced soil erosion.

\subsection{IRM Component Analysis: Mapping the Spatial Quantification of the Magnetic Carriers} 3.4.1. Case Study of the Canche-Planquette River Confluence

The LT remanence data of the four selected samples form site $\mathrm{C} 2$ (section 3.1.) identified magnetite as the dominant low-coercivity component and two distinct high-coercivity components, goethite and hematite. These three mineral components were used as a priori knowledge to unmix the IRM acquisition curves following the method of Kruiver et al. (2001).

The IRM unmixing results for the five seasonal sampling campaigns are shown in Figure 12. We observe that the remanence carried by the high-coercivity (HC) fraction is more important in spring 2016, summer 2016, and autumn 2016 than in winters of 2015 and 2016 for the sampled periods. For example, at point T3, the winter 2015 Planquette River sample (T3) shows that $68 \%$ of the IRM is carried by a HC component and 

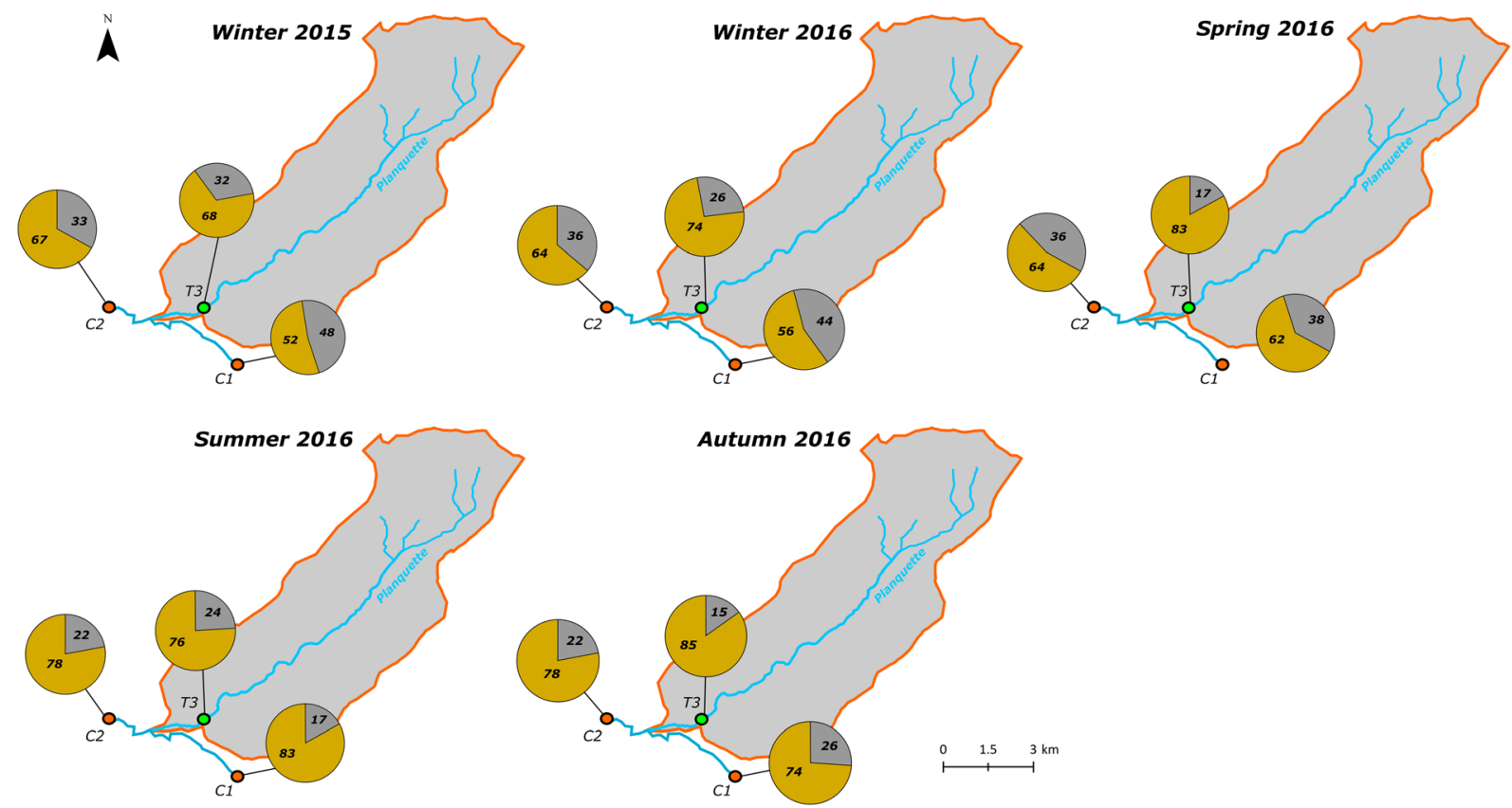

Figure 12. Results of the component analysis of IRM acquisition curves for the five different seasons between 2015 and 2016 . Pie charts color code: brownish $=$ high coercivity components in $\%$; gray $=$ low-coercivity components in $\%$. Sample site $\mathrm{C} 1$ is located upstream of the Canche-Planquette confluence. Sample site T3 is in the lower part of the Planquette catchment. Sample site C2 is located downstream of the Canche-Planquette confluence.

$32 \%$ by the LC component. In autumn 2016, at the same site (T3), $85 \%$ of the IRM is carried by HC minerals and $15 \%$ by LC minerals. We observed that the remanence carried by the HC component at the outlet of the Planquette (T3) is generally greater than in the Canche River, except for summer 2016 where the two values are approximately equal. We also observe that the $\mathrm{HC}$ remanence fraction is generally greater in the downstream part of the Canche (C2) indicating mixing of the signal between the upstream part of the Canche (C1) and the Planquette (T3). For the specific flood event of winter 2017 (Figure 14), results showed that the HC remanence component is greatest in surface runoff ( $>76 \%)$ compared to channel banks and river beds (48-73\%). For this event, SPM samples also show a high contribution of the HC remanence fraction $(>70 \%)$ indicating the transfer of soil surface particles in the stream water suspended load. This result supports the hypothesis that the HC component traces soil erosion.

Channel bank and river bed deposits store previously eroded material, available for resuspension and therefore are another potential sediment source of SPM in the water column that must be considered in the evaluation of the HC component as a tracer of surface soil erosion. Maher (1998) highlights that once soils become waterlogged dissolution of magnetic minerals can occur (e.g., resulting in low concentrations of magnetic minerals). To this end, IRM acquisition curves of the samples show that the HC component is greatest in surface runoff samples $(>76 \%)$ compared to channel banks and river bed values $(48-73 \%$; Figure 13c). The magnetic concentration $\left(M_{\mathrm{s}}\right.$, Figure 13a) and magnetic mineralogy ( $S$ ratio, Figure 13b) of these different sample types show that surface runoff samples are characterized by the lowest magnetic concentrations and the lowest $S$ ratios. Surface runoff samples thus have a high proportion of their IRM carried by goethite and hematite compared to the channel bank and river bed samples. This is consistent with the fact that surface runoff samples are recovered in the Venturi channel at the outlet of the Pommeroye catchment during the actual flood event and thus represent the direct runoff of the drained agricultural fields just upstream the Venturi channel.

The channel bank samples and river bed samples ( $\mathrm{Cb} 1-3$ and $\mathrm{Rb} 1-3)$ all show higher $M_{\mathrm{s}}$ and $S$ ratio values, indicating a greater contribution of magnetite. Channel bank and river bed deposits being a less oxic environment than that of surface soils, a higher proportion of more reduced iron oxide phases, such as magnetite, is coherent. 


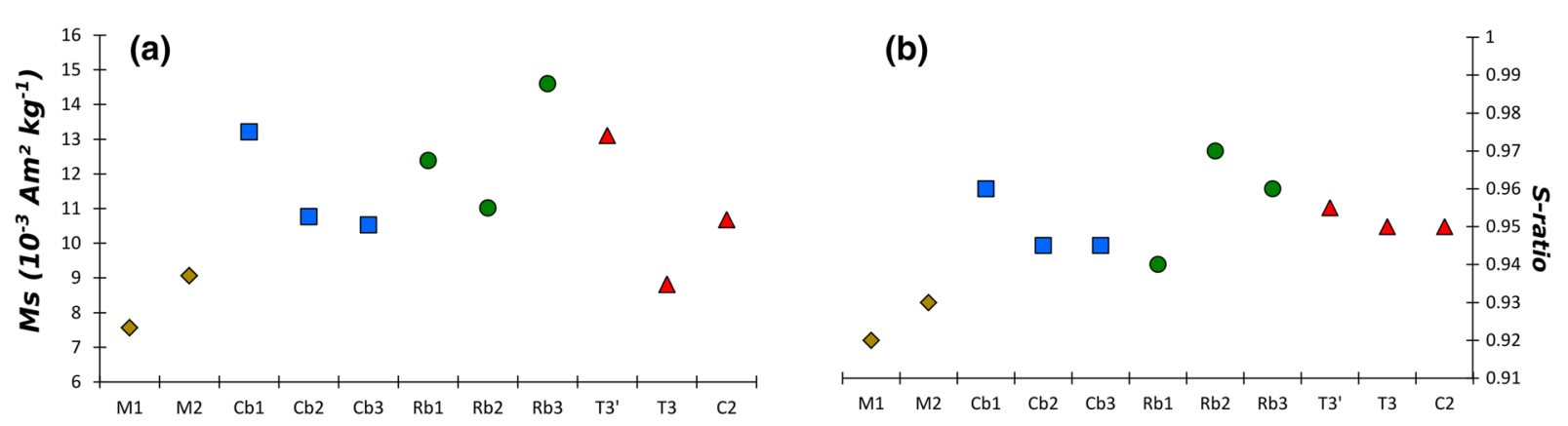

$\diamond$ Surface run-off
$\square$ Channel bank
$\bigcirc$ River bed
$\Delta$ Suspended matter

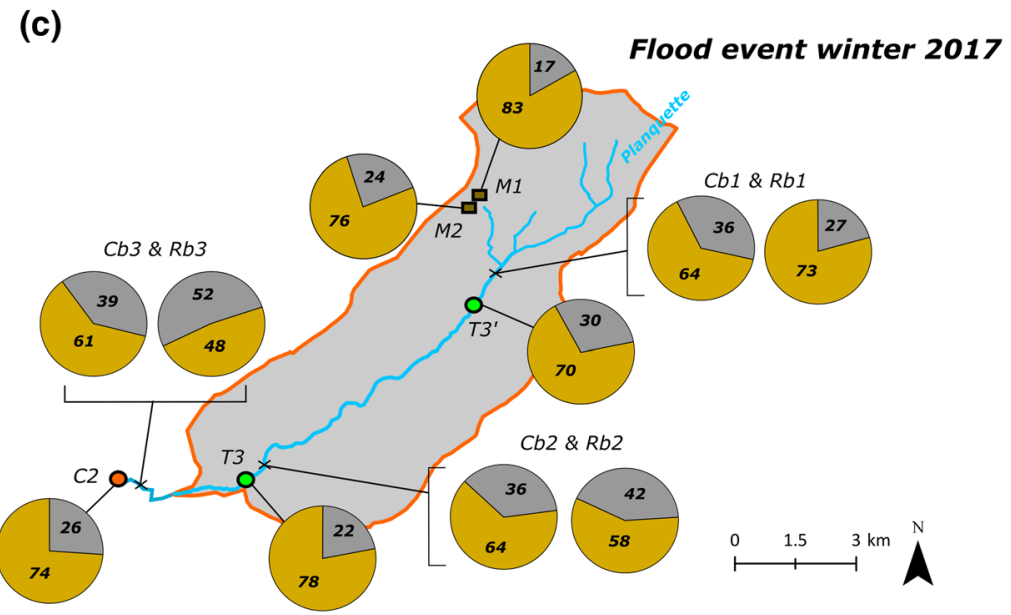

Figure 13. (a) Results of the component analysis of IRM acquisition curves of the flood event in winter 2017 and (b, c) magnetic parameters of the sediment samples of the flood event. Pie charts color code: brownish $=$ high coercivity components in \%; gray = low-coercivity components in $\%$. Signification of acronyms: $\mathrm{T}=$ tributary; $\mathrm{C}=$ confluence; $\mathrm{M}=$ surface runoff; $\mathrm{Cb}=$ channel bank; and $\mathrm{Rb}=$ river bed. Samples sites $\mathrm{T} 3, \mathrm{~T} 3^{\prime}, \mathrm{M} 1, \mathrm{M} 2, \mathrm{Cb} 1, \mathrm{Rb} 1, \mathrm{Cb} 2$, and $\mathrm{Rb} 2 \mathrm{are}$ in the upper and lower parts of the Planquette catchment. Sample sites C2, Cb3, and Rb3 are located downstream of the Canche-Planquette confluence.

The SPM samples at point T3', T3, and C2 (Figure 1) have $M_{\mathrm{S}}$ and $S$ ratio values similar to those of the channel bank and river bed samples. However, IRM unmixing results indicate that SPM at T3', T3, and C2 have slightly higher proportion of $\mathrm{HC}$ component ( $70 \% \mathrm{HC}$ and $30 \% \mathrm{LC}$ ) suggesting that the SPM at these sites have contributions from both runoff material and deposited material (channel banks and river bed).

Results presented so far demonstrate that high-coercivity minerals are present in higher concentration in runoff transported eroded topsoil during rainfall events enabling the use of an IRM unmixing approach at the scale of a watershed.

\subsubsection{Seasonal Mapping on the Canche Watershed Scale}

The IRM component analysis focusing on the area of the Canche-Planquette confluence (section 3.4.1.) supports our interpretation of the $\mathrm{HC}$ fraction as a tracer for soil erosion/sediment flux obtained from the analysis of hysteresis parameters. In the following, we attempt an upscaling to monitor the sediment flux mapped along a linear Canche River catchment profile. Therefore we use a larger data set of spatiotemporal variations in magnetic concentration $\left(M_{\mathrm{S}}\right)$ and magnetic mineralogy $(S$ ratio) during the afore mentioned five sampling seasons.

Figure 14 presents the spatiotemporal results for both, the $M_{\mathrm{s}}$ and $S$ ratio parameters along the upstream to downstream profile for all five seasonal sampling campaigns. The continuous blue line in the figure panels shows the mean water discharge along the profile with respect to the seasonal water conditions during the respective sampling campaign. Note that solely the winter 2015 and winter 2016 sampling campaigns fall within periods of high water discharge (compare to Figure 4). During the spring and summer $2016 \mathrm{cam}$ paigns the river had intermediate water conditions, whereas the autumn 2016 campaign corresponds to a low-water stand. 


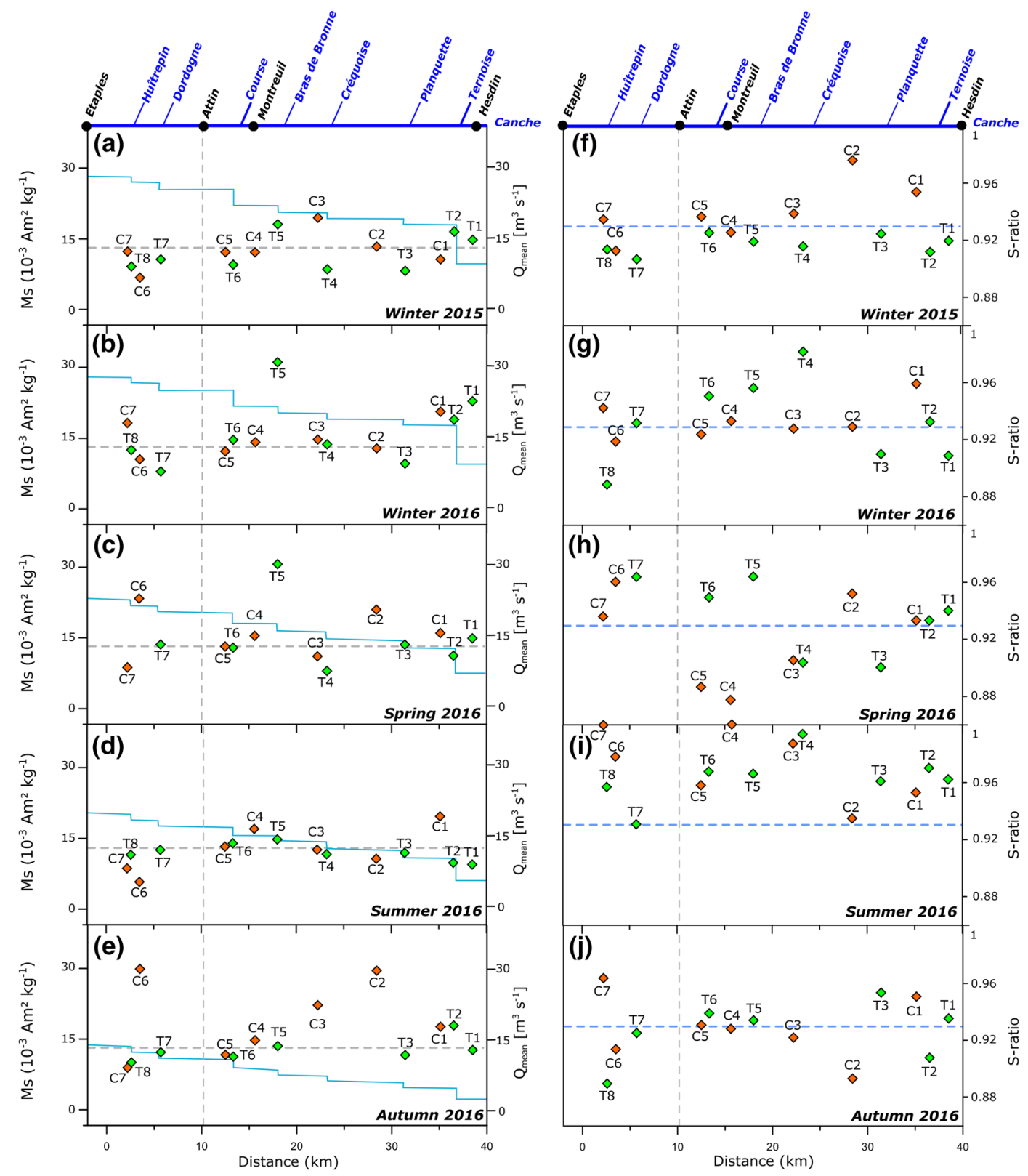

Figure 14. (a-j) Magnetic concentration $\left(\mathrm{M}_{\mathrm{S}}\right)$ and $S$ ratio along the Canche River for the five seasonal sampling campaigns.

In all sampled seasons the magnetic concentration of the Canche River is slightly below or close to an empirical value of $14 \times 10^{-3} \mathrm{Am}^{2} \mathrm{~kg}^{-1}$, which is highlighted for orientation purposes in all graph $M_{\mathrm{s}}$ panels of Figure 14 as a gray dotted line. This value corresponds to the mean value $\left(M_{\mathrm{s}_{-} \text {mean }}\right)$ of all five analyzed SPM from sediment trap samples, whatever the water discharge conditions. Only $25 \%$ of all individual $M_{\mathrm{s}}$ values lie above this line. This observation seams independent of the respective water discharge during the sampling season. Under the hypothesis that this threshold presents a sort of "empirical background signal" of the magnetic concentration in the Canche River catchment, we may consider that samples that show distinctively higher $M_{\mathrm{s}}$ values, are outliers of this general background trend of the fresh water Canche transect (between Hesdin and Attin, location see Figure 1).

Results of sample sites downstream of Attin (points T7, C6, T8, and C7) fall into the area which is strongly influenced by tide activity of the English Channel. In this zone, the $M_{\mathrm{S}}$ values of the downstream tributary 
rivers Dordogne (T7) and Huîtrepin (T8) are always below the so-called background line, which is not the case for the sample sites directly downstream of Canche (C6 and $\mathrm{C} 7$ ) that show strong variations of their magnetic concentration values.

In general, the quantity of the transported suspended material is controlled by the water flow (Hickin, 1995; Knighton, 1998; Williams, 1989). For the Seine River, Estèbe (1996) and Vilmin (2014) state short concentrations peaks in SPM when flooding passes a certain threshold (that might be individual for each river). Estèbe (1996) also state that the total flux of transported iron is proportional to the total SPM, leading Kayvantash (2016) to deduce that the concentration in magnetic minerals should not be biased. In fact, Kayvantash et al. (2017) studied an upstream section of the Seine River following the same sampling protocol as for our present study of the Canche River. The environmental magnetic results for the upstream Seine River section showed that sampling was representative for the granulometric fraction of the respective low-water and high-water conditions and the recovered magnetic fraction. Kayvantash (2016) also state that variations in magnetic concentrations $\left(M_{\mathrm{s}}\right)$ at the studied upstream site in the Seine River (Marnay) are between 3.2 and $15.3 \times 10^{-3} \mathrm{Am}^{2} \mathrm{~kg}^{-1}$ depending on the respective sample period. Rock magnetic analyses showed a magnetite dominated magnetic assemblage, with a mean $S$ ratio close to 1 suggesting a minor contribution of goethite and hematite. As stated above, the annual sediment flux at the Canche estuary (Artois-Picardie Water Agency) is estimated at 29-185 kt yr ${ }^{-1}$ for the period between 1998-2016. Using the sediment fingerprinting model applied in Patault, Alary, Franke, and Abriak (2019), the calculated the sediment flux contributions for the different tributaries in the Canche River catchment, ranging from 0.87 to $40.7 \mathrm{kt} \mathrm{yr}^{-1}$.

From the interpretation of the IRM unmixing results in section 3.4.1. (Figure 12), that zoom on the Planquette-Canche confluence, we concluded that the magnetic signal is carried here by a relatively high percentage of HC components (between 52-85\%). Thus, when regarding the magnetic concentration parameter $\mathrm{M}_{\mathrm{s}}$, we need to keep in mind the fact that $\mathrm{M}_{\mathrm{s}}$ might be carried by varying proportions of magnetite and $\mathrm{HC}$ magnetic carriers. The combination of $\mathrm{M}_{\mathrm{s}}$ and $S$ ratio is therefore helpful to estimate not only the concentration of magnetic particles but also the mixing of the different magnetic carriers in the respective SPM sample (e.g., Frank \& Nowaczyk, 2008). The $S$ ratio of the five sampled seasons in the Canche River (Figures 14f-14j) show a pure magnetite composition $(S$ ratio $=1)$ only for the sampling sites $C 4$ and $\mathrm{C} 7$ in summer 2016, all other spatiotemporal samples show $S$ ratios $<1$.

Thus, as already employed for the $M_{\mathrm{S} \_ \text {mean }}$ parameter before, we calculated an "empirical marker value" that corresponds to the mean value of the $S$ ratio $\left(S\right.$ ratio $\left._{\text {mean }}=0.93\right)$ for all SPM samples (gray dotted line in

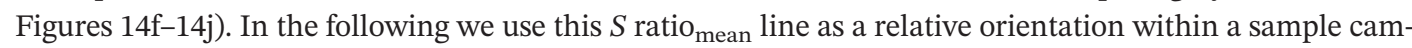
paign and between the different seasons.

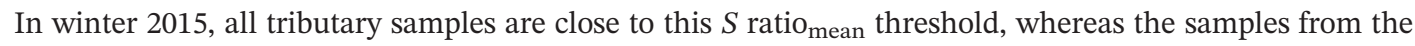
main river Canche clearly lie above this line. In winter 2016, this trend seems inversed for most of the samples, despite the very upstream and downstream tributary sites (T1, T3, and T8). In spring 2016, only the Planquette site T3 and the middle part of the Canche samples (C3-C5) show values below $S$ ratio $<0.92$. In summer 2016, all samples show values above $S$ ratio $>0.92$, whereas in autumn 2016 all samples show values between 0.96 and 0.92 , with exception of $\mathrm{T} 2, \mathrm{C} 2, \mathrm{C} 6$, and $\mathrm{T} 8$. If we now try to resume the combination of the two possible offsets from the mean background trend lines for magnetic concentration and magnetic mineralogy, in terms of river conditions, values with $\mathrm{M}_{\mathrm{S}}$ far from the background line and with very low $S$ ratios should correspond to samples of high particle flux and high proportions of HC minerals.

In contrast, the sample set of summer 2016 shows only a small offset from the background line(s) would then correspond the closest to a "no erosion scenario" in the Canche River catchment, which is confirmed by the intermediate to decreasing water discharge and no-rain fall conditions during this time period (Figure 4). $M_{\mathrm{S}}$ values of this season have a mean magnetic mineralogy close to an $S$ ratio $\sim 0.96$. Comparing this to the results from section 3.4.1, e.g., Figures $12 \mathrm{~b}$ and $12 \mathrm{c}$ point Rb3 this corresponds approximately to an IRM unmixing of $48 \% \mathrm{HC}$ and $52 \%$ LC components.

Therefore we assume that as soon as runoff conditions change due to rainfall events that drain the topsoil into the surface water, a larger contribution of $\mathrm{HC}$ components is obtained in the SPM samples and $S$ ratio values drop. Depending on weather conditions in a given season, this might be a very local rainfall event, 
restricted to a small area of the catchment. For example in winter $2016 S$ ratio values are lower (i.e., higher runoff) only for upstream sites (Ternoise and Planquette tributaries) and similarly in spring 2016 where $S$ ratios were low for sites in the middle of the Canche catchment. Site T5 in spring 2016 shows high magnetic concentration values and $S$ ratio values attests to an additional input of a LC component originating from channel bank or river bed sediments. The spatiotemporal mapping of winter 2015 and autumn 2016 corresponds to catchment-wide rainfall events during which runoff eroded surface soil particles reached all sample sites in the Canche catchment.

\section{Discussion and Conclusion}

Many studies on suspended sediments in fluvial systems use a multitude of different tracers to identify sources and to quantify the flux in a given catchment. Sediment fingerprinting approaches struggle with the fact that the comparison of source material and suspended load is not always evident (grain size effects or organic matter corrections, diagenetic alterations, conservative behavior, spatial variations, statistical underrepresentation; e.g., Pulley et al., 2015; Laceby et al., 2017) and many criterions must be fulfilled to run robust unmixing models. This usually imposes huge logistical and budgetary efforts to the respective study. Therefore, straightforward and easily applied methods offer facilitation to environmental management of catchments.

The presented nondestructive environmental magnetic methods (RT hysteresis analyses in combination with LT MPMS experiments) provide a tool to treat a relatively large number of samples, even in small material quantity without any laborious sample preparation. The achieved parameters may then serve as robust tracers to run unmixing or confluence-based sediment fingerprinting models to calculate sediment flux budgets. Magnetic tracers are robust under the condition that the ferruginous (iron-bearing) fraction sampled is representative, the spatiotemporal sampling frequency is adapted to the hydrodynamic regime of the studied catchment and some calibration (ground truthing) of the magnetic parameters is undertaken.

This study focuses on estimating inputs within the Canche River catchment of sediment originating from agricultural soils eroded by runoff using variations in magnetic mineralogy assemblages. Comparison with $M_{\mathrm{S}}$ and $S$ ratio values from the rural upstream area of the Seine River watershed (Kayvantash, 2016; Kayvantash et al., 2017) are in the same range of order, possibly due to the fact that the drained lithologic units of the Paris Basin (marley silts and chalks) are very similar to those of the Canche River catchment that corresponds also to the upstream Seine River size channel/mean flow rate. In comparison, other similar sized agricultural catchments with various background lithology state published (S)IRM values for the Jackmoor Brook basin, SW England UK (SIRM = 2.5 to $9 \times 10^{-3} \mathrm{Am}^{2} \mathrm{~kg}^{-1}$; Walling et al., 1979), several small rivers in New South Wales Australia, (IRM $=1$ to $8 \times 10^{-3} \mathrm{Am}^{2} \mathrm{~kg}^{-1}$; Caitcheon, 1993), a small agricultural basin in Oxfordshire UK (IRM = 1.5 to $4.4 \mathrm{Am}^{2} \mathrm{~kg}^{-1}$; Slattery et al., 1995), the Slapton Ley/Old Mill catchment in South Devon UK, (IRM $=4$ to $10 \times 10^{-3} \mathrm{Am}^{2} \mathrm{~kg}^{-1}$; Foster et al., 1998), the Leadon River catchment in Herefordshire UK (IRM $=6$ to $0.02 \times 10^{-3} \mathrm{Am}^{2} \mathrm{~kg}^{-1}$; Gruszowski et al., 2003), the Bassenthwaite catchment in Cumbria, UK (SIRM $=21$ to $37 \times \mathrm{Am}^{2} \mathrm{~kg}^{-1}$; Hatfield \& Maher, 2008), and several small sandy rivers from Martinique Island (SIRM = 159 to $17 \times 10^{-3} \mathrm{Am}^{2} \mathrm{~kg}^{-1}$; Salomé \& Meynadier, 2004),

Thus the conclusions of Kayvantash et al. (2017) on the grain size dependence between magnetic fraction and bulk sediment as well as the assumptions on the deconvolution between runoff and base flow in the studied meander belt of the upstream Seine River may be taken into account for comparable fluvial systems, such as the Canche River as shown by the respective grain size analyses shown in section 4.2. Our results highlight that $S$ ratio values of a given sample site are sensitive to local weather conditions during the sampling period. Thus, interpretations of the $S$ ratio at a given site, requires that a catchment-wide "no erosion background value" be determined that may differ depending on the hydrodynamic regime of the river and the lithology and topography of the catchment. Thereafter, positive or negative variations of HC and LC component input can be observed and interpreted as inputs of specific sources eroded into the river water column (surface soil particle or channel banks/river bed deposits), which is of particular interest for quantifying relative sediment flux.

The present study shows the potential and limits of the employed environmental magnetic parameters as a function of the different tested spatiotemporal scales and sampling campaign design. For example, it is 
feasible to perform high-resolution snapshot sampling during distinct flood events when focusing on a small catchment area, such as the Planquette-Canche confluence, or when disposing of an automated sampling station such as at Attin or at the outlet of the Pommeroye catchment. Snapshot sampling of an entire catchment such as the Canche River is a heavy logistical and financial burden; regular seasonal sampling campaigns are better adapted if sampling sites are chosen strategically and deemed representative. If possible, water flow and velocity, and precipitation rates must be considered when interpreting the signal of transported particles caught in the sediment traps. Ideally, these conditions should be constant during the sampling period if conclusions on the sediment flux are to be drawn. The optimum between sampling logistics and spatiotemporal resolution must be adapted with respect to the catchment size and reactivity of the fluvial system.

Comparison with other complementary rapid nondestructive techniques, such as spectrocolorimetry would be interesting, since the latter technique detects the HC magnetic minerals hematite and goethite (e.g., Balsam et al., 2014; Debret et al., 2011; Torrent \& Barrón, 2003) in addition to other sediment components (quartz, carbonates, clay minerals, etc). As observed in Patault (2018), the soil sample color signature in the Canche River catchment is typical of the goethite, which supports our interpretation of the $S$ ratio magnetic parameter as a tracer of soil surface erosion.

\section{Acknowledgments}

This work was financially supported by the Institute Mines-Telecom Lille-Douai, with additional funding provided by the Water Agency of Artois-Picardie (QUASPER project) and by the Institute Carnot-M.I.N.E.S. (FluvioMagTrack project). We would also like to acknowledge technical support from Emilie Delattre, Jordan Délépine (SYMCEA), and François Derancourt (regional Chamber of Agriculture Nord-Pas-de-Calais, France). Authors are grateful to the LSCE and the IPGP (paleo)magnetism groups for the opportunity to access the respective magnetic equipment. Data sets for this research are included in this paper (and its supporting information) which can be downloaded from the Zenedo open access platform (https://doi.org/10.5281/ zenodo.3738995).

\section{References}

Andréassian, V., Lerat, J., le Moine, N., \& Perrin, C. (2012). Neighbors: Nature's own hydrological models. Journal of Hydrology, 414-415, 49-58. http://doi.org/10.1016/j.jhydrol.2011.10.007

Balsam, W., Ji, J., Renock, D., Deaton, B., \& Williams, E. (2014). Determining hematite content from NUV/Vis/NIR spectra: Limits of detection. American Mineralogist, 99, 2280-2291.

Butler, R. F., \& Banerjee, S. K. (1975). Theoretical single-domain grain size range in magnetite and titanomagnetite. Journal of Geophysical Research, 80, 4049-4058.

Caitcheon, G. G. (1993). Sediment source tracing using environmental magnetism: A new approach with examples from Australia. Hydrological Processes, 7(4), 349-358. http://doi.org/10.1002/hyp.3360070402

Carter, J., Owens, P., Walling, D., \& Leeks, G. (2003). Fingerprinting suspended sediment sources in a large urban river system. The Science of the Total Environment, 314-316(03), 513-534. http://doi.org/10.1016/S0048-9697(03)00071-8

Dearing, J. (1987). Environmental magnetism. Quaternary Science Reviews, 6. http://doi.org/10.1016/0277-3791(87)90024-2

Debret, M., Sebag, D., Desmet, M., Balsam, W., Copard, Y., Mourier, B., et al. (2011). Spectrocolorimetric interpretation of sedimentary dynamics: The new "Q7/4 diagram”. Earth-Science Reviews, 109, 1-19. http://doi.org/10.1016/j.earscirev.2011.07.002

Dekkers, M. J. (1989). Magnetic properties of natural geothite-II. TRM behavior during thermal and alternating field demagnetization and low-temperature treatment. Geophysical Journal International, 97(1989), 341-355.

Dunlop, D. J., \& Özdemir, Ö. (1997). Rock magnetism, fundamentals and frontiers, (p. 573). Cambridge: Cambridge University Press.

Estèbe, A., (1996). Impact de l'agglomeration parisienne et de ses rejets par temps de pluie sur les co,centrations de métaux de matières en suspension et des sédiments en Seine en période estivale. Ph.D. thesis, Université Paris XII - Val de Marne.

Evans, M. E., \& Heller, F., (2003). Environmental magnetism. Principles and applications of environmagnetics (Vol. 86, pp. 299). Elsevier Sciences.

Evrard, O., Némery, J., Gratiot, N., Duvert, C., Ayrault, S., Lefèvre, I., et al. (2010). Sediment dynamics during the rainy season in tropical highland catchments of central Mexico using fallout radionuclides. Geomorphology, 124(1-2), 42-54. http://doi.org/10.1016/j. geomorph.2010.08.007

Foster, I. D. L., Lees, J. A., Owens, P. N., \& Walling, D. E. (1998). Mineral magnetic characterization of sediment sources from an analysis of lake and floodplain sediments in the catchments of the Old Mill Reservoir and Slapton ley, South Devon, UK. Earth Surface Processes and Landfroms, 23, 685-703.

Frank, U., \& Nowaczyk, N. R. (2008). Mineral magnetic properties of artificial samples systematically mixed from haematite and magnetite. Geophysical Journal International, 175, 449-461. https://doi.org/10.1111/j.1365-246X.2008.03821.x

Franke, C., Kissel, C., Robin, E., Bonté, P., \& Lagroix, F. (2009). Magnetic particle characterization in the seine river system: Implications for the determination of natural versus anthropogenic input. Geochemistry, Geophysics, Geosystems, 10, 4. http://doi.org/10.1029/ 2009GC002544

Gruszowski, K. E., Foster, I. D. L., Lees, J. A., \& Charlesworth, S. M. (2003). Sediments sources and transport pathways in a rural catchment, Herefordshire, UK. Hydrological Processes, 17, 2665-2681. https://doi.org/10.1002/hyp.1296

Guyodo, Y., Banerjee, S. K., Penn, R. L., Burleson, D., Berauo, T. S., Seda, T., \& Solheid, P. (2006). Magnetic properties of synthetic six-line ferrihydrite nanoparticles. Physics of the Earth and Planetary Interiors, 154(3-4), 222-233.

Guyodo, Y., Mostrom, A., Penn, R. L., \& Banerjee, S. K. (2003). From nanodots to nanorods: Oriented aggregation and magnetic evolution of nanocrystalline goethite. Geophysical Research Letters, 30(10), 1512. https://doi.org/10.1029/2003GL017021

Guzmán, G., Quinton, J. N., Nearing, M. A., Mabit, L., \& Gómez, J. A. (2013). Sediment tracers in water erosion studies: Current approaches and challenges. Journal of Soils and Sediments, 13(4), 816-833. http://doi.org/10.1007/s11368-013-0659-5

Haddadchi, A., Ryder, D. S., Evrard, O., \& Olley, J. (2013). Sediment fingerprinting in fluvial systems: Review of tracers, sediment sources and mixing models. International Journal of Sediment Research, 28(4), 560-578. http://doi.org/10.1016/S1001-6279(14) 60013-5

Hatfield, R. G., \& Maher, B. A. (2008). Suspended sediment characterization and tracing using a magnetic fingerprinting technique: Bassenthwaite Lake, Cumbria, UK. The Holocene, 18(1), 105-115. https://doi.org/10.1177/0959683607085600

Heslop, D. (2015). Numerical strategies for magnetic mineral unmixing. Earth-Science Reviews, 150, 256-284.

Hickin, E. J. (1995). River geomorphology, Publication International Association of Geomorphologists. New York: Wiley. 
Kayvantash, D. (2016). Caractérisation des particules ferrugineuses dans la Seine avec le magnétisme environnemental. Ph. D. thesis, PSL Research University, France.

Kayvantash, D., Cojan, I., Kissel, C., \& Franke, C. (2017). Magnetic fingerprint of the sediment load in a meander bend section of the Seine River (France). Geomorphology, 286, 14-26. http://doi.org/10.1016/j.geomorph.2017.02.020

King, J. W., \& Channell, J. E. T. (1991). Sedimentary magnetism, environmental magnetism, and magnetostratigraphy. Reviews of Geophysics, Supplement (August), 29, 358-370.

Knighton, D. (1998). Fluvial forms and processes: A new perspective. London: Arnold.

Kosterov, A. (2003). Low-temperature magnetization and AC susceptibility of magnetite: Effect of thermomagnetic history. Geophysical Journal International, 154(1), 58-71. http://doi.org/10.1046/j.1365-246X.2003.01938.x

Kruiver, P. P., Dekkers, M. J., \& Heslop, D. (2001). Quantification of magnetic coercivity components by the analysis of acquisition curves of isothermal remanent magnetisation. Earth and Planetary Science Letters, 189(3-4), 269-276. http://doi.org/10.1016/S0012-821X(01) 00367-3

Laceby, J. P., Evrard, O., Smith, H. G., Blake, W. H., Olley, J. M., Minella, J. P. G., \& Owens, P. N. (2017). The challenges and opportunities of addressing particle size effects in sediment source fingerprinting: A review. Earth-Science Reviews, 169, 85-103. http://doi.org/ 10.1016/j.earscirev.2017.04.009

Lagroix, F., \& Guyodo, Y. (2017). A new tool for separating the magnetic mineralogy of complex mineral assemblages from low temperature magnetic behavior. Frontiers in Earth Science, 5(July), 1-11. http://doi.org/10.3389/feart.2017.00061

Lawrimore, Jay H.; Ray, Ron; Applequist, Scott; Korzeniewski, Bryant; Menne, Matthew J. (2016): Global Summary of the Year (GSOY), Version 1. [indicate subset used]. NOAA National Centers for Environmental Information. https://doi.org/10.7289/JWPF-Y430. Accessed 09/13/2019.

Le Gall, M., Evrard, O., Foucher, A., Laceby, J. P., Salvador-Blanes, S., Thil, F., et al. (2016). Quantifying sediment sources in a lowland agricultural catchment pond using $137 \mathrm{Cs}$ activities and radiogenic ${ }^{87} \mathrm{Sr} /{ }^{86} \mathrm{Sr}$ ratios. Science of the Total Environment, 566-567, 968-980. http://doi.org/10.1016/j.scitotenv.2016.05.093

Lowrie, W., \& Heller, F. (1982). Magnetic properties of marine limestones. Reviews of Geophysics, 20(2), 171-192. http://doi.org/10.1029/ RG020i002p00171

Maher, B. A. (1998). Magnetic properties of modern soils and quaternary loessic paleosols: Paleoclimatic implications. Palaeogeography Palaeoclimatology Palaeoecology, 137, 25-54.

Maher, B. A. (2007). Environmental magnetism and climate change. Contemporary Physics, 48(5), 247-274. http://doi.org/10.1080/ 00107510801889726

Maher, B. A., Watkins, S. J., Brunskill, G., Alexander, J., \& Fielding, C. R. (2009). Sediment provenance in a tropical fluvial and marine context by magnetic "fingerprinting" of transportable sand fractions. Sedimentology, 56(3), 841-861. http://doi.org/10.1111/ j.1365-3091.2008.00999.x

Martínez-Carreras, N., Krein, A., Gallart, F., Iffly, J. F., Pfister, L., Hoffmann, L., \& Owens, P. N. (2010). Assessment of different colour parameters for discriminating potential suspended sediment sources and provenance: A multi-scale study in Luxembourg. Geomorphology, 118(1-2), 118-129. http://doi.org/10.1016/j.geomorph.2009.12.013

Motha, J. A., Wallbrink, P. J., Hairsine, P. B., \& Grayson, R. B. (2004). Unsealed roads as suspended sediment sources in an agricultural catchment in south-eastern Australia. Journal of Hydrology, 286(1-4), 1-18. http://doi.org/10.1016/j.jhydrol.2003.07.006

Oldfield, F., Rummery, T. A., Thompson, R., \& Walling, D. E. (1979). Identification of suspended sediment sources by means of magnetic measurements: Some preliminary results. Water Resources Research, 15(2).

Ozdemir, O., \& Dunlop, D. J. (1996). Thermoremanence and Néel temperature of goethite. Geophysical Research Letters, 23(9), 921-924.

Özdemir, Ö., Dunlop, D. J., \& Moskowitz, B. M. (1993). The effect of oxidation on the Verwey transition in magnetite. Geophysical Research Letters, 20(16), 1671-1674. http://doi.org/10.1029/93GL01483

Özdemir, Ö., Dunlop, D. J., \& Moskowitz, B. M. (2002). Changes in remanence, coercivity and domain state at low temperature in magnetite. Earth and Planetary Science Letters, 194(3-4), 343-358. http://doi.org/10.1016/S0012-821X(01)00562-3

Patault, E., (2018). Analyse multi-échelle des processus d'érosion hydrique et de transferts sédimentaires en territoire agricole: exemple du bassin versant de la Canche (France), joint Ph.D. thesis 2016, IMT Lille-Douai - Département Génie Civil et Environnemental \& MINES ParisTech - Centre de Géosciences, France. http://theses.fr/2018MTLD0003

Patault, E., Alary, C., Franke, C., \& Abriak, N.-E. (2019). Quantification of sub-basin contributions using a confluence-based sediment fingerprinting approach on the Canche river catchment (France). Science of the Total Environment, 668, 457-469. https://doi.org/ 10.1016/j.scitotenv.2019.02.458

Patault, E., Alary, C., Franke, C., Gauthier, A., \& Abriak, N.-E. (2019). Assessing temporal variability and controlling factors of the sediment budget of a small agricultural catchment in northern France (the Pommeroye). Heliyon, 5(3), e01407. https://doi.org/10.1016/j. heliyon.2019.e01407

Poulenard, J., Perrette, Y., Fanget, B., Quetin, P., Trevisan, D., \& Dorioz, J. M. (2009). Infrared spectroscopy tracing of sediment sources in a small rural watershed (French Alps). Science of the Total Environment, 407(8), 2808-2819. http://doi.org/10.1016/j. scitotenv.2008.12.049

Pulley, S., Foster, I., \& Antunes, P. (2015). The application of sediment fingerprinting to floodplain and lake sediment cores: Assumptions and uncertainties evaluated through case studies in the Nene Basin, UK. Journal of Soils and Sediments, 15(10), 2132-2154. http://doi. org/10.1007/s11368-015-1136-0

Robertson, D. J., \& France, D. E. (1994). Discrimination of remanence-carrying minerals in mixtures, using isothermal remanent mag netisation acquisition curves. Physics of the Earth and Planetary Interiors, 82(3-4), 223-234. http://doi.org/10.1016/0031-9201(94) 90074-4

Russell, M., Walling, D., \& Hodgkinson, R. (2001). Suspended sediment sources in two small lowland agricultural catchments in the UK. Journal of Hydrology, 252(1-4), 1-24. http://doi.org/10.1016/S0022-1694(01)00388-2

Salomé, A.-L., \& Meynadier, L. (2004). Magnetic properties of rivers sands and rocks from Martinique Island: Tracers of weathering? Physics and Chemistry of the Earth, 29, 933-945. https://doi.org/10.1016/j.pce2004.06.002

Shah, V. K., \& Wakai, R. T. (2013). A compact, high performance atomic magnetometer for biomedical applications. Physics in Medicine and Biology, 58(22), 8153-8161. http://doi.org/10.1088/0031-9155/58/22/8153

Slattery, M. C., Burt, T. P., \& Walden, J. (1995). The application of mineral magnetic measurements to quantify within-storm variations in suspended sediment sources. Geography, 229.

Tessier, L. (2003). Transport et caractérisation des matières en suspension dans le bassin versant de la Seine: identification de signatures naturelles et anthropiques. Ph.D. thesis, Ecole des Ponts ParisTech, France. 
Theuring, P., Collins, A. L., \& Rode, M. (2015). Source identification of fine-grained suspended sediment in the Kharaa River basin, northern Mongolia. Science of the Total Environment, 526(APRIL), 77-87. http://doi.org/10.1016/j.scitotenv.2015.03.134

Torrent, J., \& Barrón, V. (2003). The visible diffuse reflectance spectrum in relation to the color and crystal properties of hematite. Clays and Clay Minerals, 51(3), 309-317. http://doi.org/10.1346/CCMN.2003.0510307

Vale, S. S., Fuller, I. C., Procter, J. N., Basher, L. R., \& Smith, I. E. (2016). Characterization and quantification of suspended sediment sources to the Manawatu River, New Zealand. Science of the Total Environment, 543(Pt A), 171-186. http://doi.org/10.1016/j. scitotenv.2015.11.003

Vilmin, L. (2014). Modélisation du fonctionnenemnt biogéochimique de la Seine de l'agglomeration parisienne à l'éstuaire à differentes échelles temporelles, Ph. D. thesis.

Walling, D. E., Peart, M. R., Oldfield, F., \& Thompson, R. (1979). Suspended sediment sources identified by magnetic measurements. Nature, 281, 110-113.

Williams, G. P. (1989). Sediment concentration versus water discharge during single hydrologic events in rivers. Journal of Hydrology, 111, 89-106. 